\title{
OPEN ACCESS Avaliação da vida útil de mamão formosa (Carica Editado por: papaya L.) minimamente processado utilizando coberturas de amido de mandioca e óleo essencial de cravo
}

Dr. Victor Hugo Gomes Sales Instituto Federal do Amapá, Macapá-AP, Brasil

Seção: Evaluation of shelf life of Formosa papaya (Carica papaya L.)

Esse artigo foi submetido em Ciência de Alimentos, uma seção do Journal of Bioenergy and Food Science

ID JBFS2692019 minimally processed using coating of cassava starch and essential clove oil

1, (iD Felipe Mateus Silva HOLSBACH, 2, (D) Sandriane PIZATO, 1, (D) Nayane Tinno FONTELES, 1, (D) Pâmela Davalos de SOUZA, 1, (D) Rosalinda Arevalo PINEDO e

DOI 10.18067/jbfs.v6i4.269 $1, *$ (D) William Renzo CORTEZ-VEGA

Processos de revisão: Prot. 2692019R01 (Brasil) Prot. 2692019R02 (Brasil)

*Autor para correspondência:

${ }^{1}$ Universidade Federal da Grande Dourados, FAEN - Faculdade de Engenharia,Rod. Dourados km 12, Itahum - 79804970. Dourados, MS - Brasil.

${ }^{2}$ Doutora em Engenharia e Ciência de Alimentos pela Universidade Federal do Rio Grande do Sul (FURG).

William Renzo Cortez-Vega williamvega@ufgd.edu.br

Conflito de interesse:

Os autores declararam que não há conflito de interesse.

Financiamento:

Os autores declararam que não receberam financiamento para o desenvolvimento da pesquisa

Recebido em: 22de maio de 2019

Aceito em: 17 de setembro de 2019

Publicado: 01 de outubro de 2019

Citation (APA) Holsbach, F.M.S, Pizato,S., Fonteles, N.T., Souza, P.D. de, Pinedo, R.A., \& Cortez-Vega, W.R. (2019). Avaliação da vida útil de mamão formosa (Carica papaya $\mathrm{L}$.)

minimamente processado utilizando

coberturas de amido de mandioca e óleo essencial de cravo. Journal of bioenergy and food science, 6(4) 78-96. doi $10.18067 / j b f s . v 6 i 4.269$

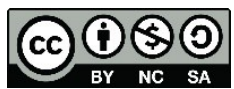

JBFS all rights Copyright: (C) 2019

\section{RESUMO}

O objetivo do presente trabalho foi avaliar a qualidade de mamão minimamente processado utilizando diferentes concentrações de amido de mandioca, glicerol e óleo essencial de cravo como revestimentos comestíveis. Os mamões foram lavados, descascados, cortados, submersos nas coberturas e drenados. Foram armazenados em embalagem PET por 15 dias a $4{ }^{\circ} \mathrm{C}$. Obtiveram-se 5 tratamentos: T1 - Controle (mamão sem revestimento); T2 - 30\% de amido, $20 \%$ de glicerol e 0,5\% de óleo essencial de cravo; T3 - 30\% de amido, 30\% de glicerol e 0,5\% de óleo essencial de cravo; T4-30\% de amido, $20 \%$ de glicerol e $1 \%$ de óleo essencial de cravo; T5 - 30\% de amido, $30 \%$ de glicerol e $1 \%$ de óleo essencial de cravo. O T1 foi o que apresentou maior perda de massa $(7,92 \%)$ e o T4, o que menos perdeu $(4,70 \%)$. Os valores de textura oscilaram com o passar dos dias. Em relação à luminosidade, os valores diminuíram com o passar dos dias. T4 foi o melhor em relação a inibição dos microrganismos psicrotróficos e bolores e leveduras. Sensorialmente o tratamento T4 apresentou as maiores notas ao final dos dias de armazenamento. Assim, o tratamento T4 foi a mais eficiente para manter a qualidade do mamão.

Palavras-chave: Qualidade. Avaliação sensorial. Mamão. Revestimentos

\section{ABSTRACT}

The objective of the present work was to evaluate the quality of minimally processed papaya using different concentrations of cassava starch, glycerol and clove essential oil as edible coatings. The papayas were washed, peeled, cut, submerged in the coatings and drained. They were stored in PET packaging for 15 days at $4{ }^{\circ} \mathrm{C}$. Five treatments were obtained: T1 - Control (papaya without coating); T2 - 30\% starch, 20\% glycerol and 0.5\% clove essential oil; T3 - 30\% starch, 30\% glycerol and $0.5 \%$ clove essential oil; T4 - 30\% starch, $20 \%$ glycerol and $1 \%$ clove essential oil; T5 - 30\% starch, 30\% glycerol and 1\% clove essential oil. T1 had the highest mass loss (7.92\%) and T4, which lost the least (4.70\%). The texture values oscillated as the storage days. In relation to the luminosity, the values decreased with the passing of storage days. T4 was the best in relation to inhibition of psychrotrophic microorganisms and molds and yeasts. Sensorially the T4 treatment was the one that obtained the highest notes at the end of the days of storage. Thus, the T4 treatment was the most efficient to maintain the quality of the papaya.

Keywords: Quality. Sensory evaluation. Papaya. Coatings 


\section{INTRODUÇÃO}

O mamão é um dos frutos mais cultivados do mundo e seu mercado vem se expandindo em função da boa aceitabilidade e das possibilidades de aproveitamento do mesmo (Mendonça et al., 2006). A produção nacional do mamão está baseada em dois grupos, o "Formosa" e o "Havaí". O mamão Formosa é destinado, principalmente, para o mercado interno, enquanto o Havaí para os mercados externo e interno (Rocha, Nascimento, Menezes, Nunes \& Silva, 2005). O primeiro, apesar de bem aceito pelo consumidor, é pouco conveniente para uso individual devido ao tamanho grande e falta de uniformidade de formato, além de exigir um preparo para o consumo, como o descasque e eliminação de sementes (Souza, Durigan, Donadon \& Lima, 2005). Por isso, neste presente trabalho, foi escolhido trabalhar com o mamão "Formosa", devido a sua forma minimamente processada ser mais conveniente para o consumidor, principalmente para pessoas que moram sozinhas.

A tendência de mudanças nos hábitos alimentares da população mundial mostra um aumento discreto no consumo de frutas e hortaliças. Entretanto, tem-se verificado a busca por alimentos com maior conveniência, ou seja, aqueles que exigem tempo reduzido de manuseio e preparo e que mantêm suas características sensoriais e nutricionais originais (Silva, Oliveira, Carnelossi, Muniz \& Narain, 2009). Neste sentido, a procura por produtos minimamente processados, tem aumentado. Estes são definidos como produtos vegetais que passaram por alterações físicas, isto é, foram descascados, picados, torneados ou ralados, dentre outros processos, mas mantidos no estado fresco e metabolicamente ativo (Moretti, 2007). No entanto, produtos minimamente processados têm uma vida útil relativamente curta, devido a cortes e à sua manipulação, o que ocasiona aumento do seu metabolismo (Perera, Gamage, Wakeling, Gamlath \& Versteeg, 2010).

Revestimentos comestíveis podem ser preparados a partir de proteínas, polissacarídeos, lipídeos ou a combinação desses componentes (Cao, Fu \& He, 2007). Em mamão inteiro ou minimamente processado tem sido utilizado como revestimentos, principalmente, agentes gelificantes como fécula de mandioca, alginato, gelana, amido de arroz, goma xantana (Pereira et al., 2006; Tapia et al., 2008; Besinela Junior et al., 2010; Trigo, Albertini, Spoto, Bruder, \& Sarmento, 2012; Cortez-Vega, Piotrowicz, Prentice \& Borges, 2013). Revestimentos comestíveis têm sido utilizados na indústria de minimamente processados como uma estratégia para reduzir os efeitos que o processamento mínimo provoca nos tecidos vegetais. Além disso, revestimentos comestíveis podem contribuir para aumentar a vida útil de frutas minimamente processadas, reduzindo a umidade e a migração do soluto, troca gasosa, respiração e reação de oxidação, bem como pode auxiliar na redução de distúrbios fisiológicos (Rojas-Graü, Soliva-Fortuny \& Martín-Belloso, 2009).

O polímero biodegradável que mais se destaca no desenvolvimento de filmes e coberturas é o amido já que ele se encontra em abundância na natureza, possui baixo custo, apresenta muitas possibilidades de modificação química e física, além de originar revestimentos resistentes. Geralmente, os filmes elaborados com amidos são quebradiços, desta forma, tem-se a necessidade da inserção de plastificantes. 0 glicerol promove um aumento no comportamento elástico dos filmes, melhorando as propriedades físicas e mecânicas, além de aumentar sua vida útil (Bergo, Sobral \& Prison, 2010). 
Além disso, é possível conciliar as coberturas comestíveis agentes conservantes para prolongar sua vida útil. Uma opção encontrada foi o uso de óleos essenciais, compostos que estão relacionados com propriedades antimicrobianas e antioxidantes. Uma vez incorporados nos polímeros e em contato com o alimento, pode ocorrer uma migração lenta e constante dos agentes bactericidas e/ou bacteriostáticos (Coma, 2008).

Os óleos essenciais são compostos complexos naturais, voláteis, caracterizados por um forte odor e constituído por metabólitos secundários de plantas aromáticas. Eles são normalmente obtidos por meio de vapor ou hidrodestilação. Conhecido pela sua atividade antisséptica, ou seja, bactericida, fungicida e virucida, propriedades medicamentosas e flavorizantes, eles são usados na conservação dos alimentos, como antibióticos, analgésicos e anti-inflamatório (Chevalier, Silva, Silva, Pizato \& Cortez-Veja, 2016).

Dessa forma, este trabalho teve como objetivo avaliar a vida útil de mamões "Formosa" minimamente processados revestidos com quatro diferentes concentrações de coberturas à base de amido de mandioca, glicerol e óleo essencial de cravo, durante 15 dias a uma temperatura de $4 \pm 1{ }^{\circ} \mathrm{C}$.

\section{MATERIAL E MÉTODOS}

\section{a) Material}

Foram utilizadas unidades de mamão "Formosa" adquiridas no comércio local da cidade de Dourados - MS. As frutas foram selecionadas quanto a massa média de, aproximadamente, $2 \mathrm{~kg}$, formato alongado, cor, estando no estádio de maturação nível 3, com $50 \%$ a $75 \%$ da casca amarela, sem defeitos fisiológicos e infecções detectáveis (Cortez-Vega et al., 2013).

Os mamões foram transportados até o Laboratório de Tecnologia da Universidade Federal da Grande Dourados, onde foram higienizados com solução de cloro orgânico a $2 \mathrm{~g} . \mathrm{L}^{-1}$, por 10 minutos. A matéria-prima foi submetida à remoção manual da casca e sementes, sendo cortada, manualmente, em pedaços padronizados de aproximadamente $2,5 \times 2,5 \mathrm{~cm}$. Em seguida, os pedaços foram enxaguados com água clorada $\left(0,2 \mathrm{~g} \mathrm{~L}^{-1}\right)$ para eliminar o suco celular extravasado. A água foi drenada por 2 a 3 minutos sobre peneiras.

\section{b) Preparo das coberturas}

Para o preparo dos revestimentos foram utilizados amido de mandioca, glicerol 99,5\% (marca Dinâmica, Brasil) e óleo essencial de cravo em diferentes proporções. Preparou-se 1 litro de solução para cada tratamento.

Foram realizados cinco tratamentos sendo as concentrações utilizadas para um apresentado na Tabela 1.

As soluções foram preparadas por dissolução lenta do amido em água destilada, sob agitação e aquecimento, até completa dissolução. Quando a temperatura da solução atingiu $50^{\circ} \mathrm{C}$ foram adicionados o glicerol e o óleo essencial de cravo, sob agitação até solubilização completa. Após 30 minutos, a solução foi resfriada a temperatura ambiente. 
Tabela 1. Concentrações utilizadas para o preparo de cada tratamento.

Table 1. Concentrations used to prepare each treatment.

\begin{tabular}{cccc}
\hline \multirow{2}{*}{ Tratamentos } & \multicolumn{3}{c}{ Componentes (\%) } \\
\cline { 2 - 4 } T1 (Controle) & Amido & Glicerol & Óleo essencial de cravo \\
T2 & - & - & - \\
T3 & 30 & 20 & 0,5 \\
T4 & 30 & 30 & 0,5 \\
T5 & 30 & 20 & 1,0 \\
\end{tabular}

Os pedaços de mamão foram totalmente submersos nas soluções por 3 minutos e drenados, utilizando-se peneiras para retirar o excesso de solução. Por fim, as amostras revestidas foram acondicionadas em embalagens de 15,5 x 13,2 $\times$ $5,5 \mathrm{~cm}$ de polietileno tereftalato (PET) com tampa (SANPACK, Brasil). O número de pedaços por embalagem foi padronizado (5 pedaços) e as embalagens foram armazenadas sob refrigeração, a $4 \pm 1{ }^{\circ} \mathrm{C}$ (Cortez-Vega et al., 2014).

As análises foram realizadas no dia do processamento considerado como dia 0 e após $1,3,5,7,9,12$ e 15 dias de armazenamento.

\section{c) Análises físico-químicas}

\section{Perda de massa}

A perda de massa foi obtida relacionando-se a diferença entre a massa inicial do mamão minimamente processado e a massa obtida ao final de cada tempo de armazenamento, de acordo com a equação:

Perda de massa $=[($ massa inicial - massa final $) /($ massa inicial $)] \times 100$.

Os resultados foram expressos em porcentagem de perda de massa.

\section{Textura}

As medidas de textura das amostras de mamão foram determinadas utilizando-se texturômetro (Stable Micro Systems, modelo TA.XT.plus, Inglaterra), fazendo-se uma compressão com ponteira cilíndrica $(0,5 \mathrm{~cm}$ de diâmetro) movimentada na velocidade de $4 \mathrm{~mm} \cdot \mathrm{s}^{-1}$ no pré-teste, $8 \mathrm{~mm} \cdot \mathrm{s}^{-1}$ no pós-teste, e 2 $\mathrm{mm} \cdot \mathrm{s}^{-1}$ de teste, até a profundidade de $5 \mathrm{~mm}$. Os resultados foram expressos em Newton (N).

\section{Acidez titulável}

A acidez titulável foi determinada titulando-se em $10 \mathrm{~g}$ de amostra homogeneizada com $100 \mathrm{ml}$ de água destilada, utilizando $\mathrm{NaOH} 0,1 \mathrm{~mol} \mathrm{~L}^{-1}$. Os resultados foram expressos em porcentagem de ácido cítrico (AOAC, 2008).

\section{Potencial Hidrogeniônico $(p H)$}

Para medida do $\mathrm{pH}$ foram utilizados $20 \mathrm{~g}$ das amostras sendo que essas foram trituradas juntamente com $100 \mathrm{~mL}$ de água destilada, em seguida realizou-se a medição utilizando um pHmetro (Marconi PA 200). A análise foi realizada segundo o método descrito pela AOAC (2008). 
Teor de sólidos solúveis totais ( $\left.{ }^{\circ} \mathrm{Brix}\right)$

Os teores de sólidos solúveis totais foram determinados a partir do extrato líquido obtido após a trituração da amostra. Utilizou-se um refratômetro de bancada (marca Abbe, UK), sem controle automático de temperatura. Os resultados foram expressos em ${ }^{\circ}$ Brix (AOAC, 2008).

Cor

A cor foi avaliada utilizando-se um colorímetro Minolta, modelo Chroma Meter CR400 (Japão) e detecção dos parâmetros: luminosidade, $L^{*}$, de 0 (preto) a 100 (branco); a* que varia de verde (-60) a vermelho (+60), b* de azul (-60) a amarelo (+60) (Minolta, 1994). Para o cálculo do ângulo de Hue $\left(\mathrm{H}^{\circ}\right)$ foi utilizado a equação:

$$
\mathrm{H}^{\circ}=\operatorname{arctg} \mathrm{b}^{*} / \mathrm{a}^{*}
$$

Onde: $\mathrm{H}^{\circ}$ : Ângulo de Hue; arctg: arco tangente; $\mathrm{b}^{*}$ : chroma $\mathrm{b}$; $\mathrm{a}^{*}$ : chroma $\mathrm{a}$.

\section{Análises microbiológicas}

Os testes microbiológicos realizados foram para microrganismos psicrotróficos, bolores e leveduras, Salmonella ssp e Escherichia coli seguindo-se a metodologia recomendada pela APHA (2001).

\section{Análise sensorial}

Para a análise sensorial foram utilizados 12 julgadores treinados. Foram avaliados para cada tratamento atributos, sendo textura, cor e aroma durante os 15 dias de armazenamento a $4{ }^{\circ} \mathrm{C}$. Foi utilizada metodologia descrita pro Chevalier, Pizato, De Lara \& Cortez-Vega (2018), onde se estabeleceu uma escala que variou de 5 a 1, onde 5 significava amostra de ótima qualidade (fresca, aromática e sem escurecimento); 4 significava amostra de boa qualidade (fresca e com leve escurecimento); 3 significava regular (pouco fresca, aroma menos acentuado e moderado escurecimentos); 2 significava ruim (a amostra não estava mais fresca e com elevado escurecimento); 1 a amostra estava péssima (sem frescor e aroma e com elevado grau de escurecimento e presença de bolores).

\section{d) Análise dos resultados}

As análises foram realizadas em duplicata e os resultados foram apresentados pela média e desvio padrão. Os resultados obtidos foram avaliados estatisticamente através de análise de variância (ANOVA) seguida do teste de Tukey a $5 \%$ de significância, utilizando o programa Statistica 6.0.

\section{RESULTADOS E DISCUSSÃO}

a) Perda de massa

A Tabela 2 apresenta os valores de perda de massa encontrados para os mamões minimamente processados avaliados por um período de 15 dias. 
Tabela 2. Perda de massa (\%) de amostras de mamão minimamente processado revestidos com diferentes proporções de glicerol e óleo essencial de cravo e armazenadas a $4 \pm 1{ }^{\circ} \mathrm{C}$, por 15 dias.

Table 2. Mass loss (\%) of minimally processed papaya samples coated with different proportions of glycerol and clove essential oil and stored at $4{ }^{\circ} \mathrm{C}$ for 15 days.

\begin{tabular}{|c|c|c|c|c|c|}
\hline \multirow{2}{*}{ Dias } & \multicolumn{5}{|c|}{ Tratamentos } \\
\hline & T1 (Controle) & $\mathrm{T} 2$ & T3 & $\mathrm{T} 4$ & T5 \\
\hline 0 & $0^{\mathrm{fA}}$ & $0^{\mathrm{fA}}$ & $0^{\mathrm{fA}}$ & $0^{\mathrm{fA}}$ & $0^{\mathrm{fA}}$ \\
\hline 1 & $1,42 \pm 0,20^{\mathrm{eA}}$ & $1,58 \pm 0,10^{\mathrm{eA}}$ & $1,28 \pm 0,08^{\mathrm{eA}}$ & $0,85 \pm 0,10^{f B}$ & $0,82 \pm 0,10^{\mathrm{eB}}$ \\
\hline 3 & $1,51 \pm 0,12^{\mathrm{eB}}$ & $1,96 \pm 0,10^{\mathrm{eA}}$ & $1,32 \pm 0,13^{e B}$ & $1,65 \pm 0,17^{\mathrm{eAB}}$ & $0,96 \pm 0,08^{\mathrm{ec}}$ \\
\hline 5 & $4,52 \pm 0,11^{\mathrm{dA}}$ & $4,26 \pm 0,17^{\mathrm{dA}}$ & $2,51 \pm 0,09^{d C}$ & $2,91 \pm 0,08^{\mathrm{dB}}$ & $1,97 \pm 0,18^{d D}$ \\
\hline 7 & $4,88 \pm 0,26^{\mathrm{dB}}$ & $5,41 \pm 0,18^{\mathrm{cA}}$ & $3,48 \pm 0,18^{\mathrm{cC}}$ & $3,49 \pm 0,11^{\mathrm{cC}}$ & $2,82 \pm 0,11^{\mathrm{CD}}$ \\
\hline 9 & $5,39 \pm 0,13^{\mathrm{cB}}$ & $6,08 \pm 0,39^{b A}$ & $3,70 \pm 0,16^{c c}$ & $3,87 \pm 0,15^{b c}$ & $3,02 \pm 0,15^{\mathrm{CD}}$ \\
\hline 12 & $7,11 \pm 0,18^{\mathrm{bA}}$ & $6,71 \pm 0,15^{\mathrm{aA}}$ & $4,39 \pm 0,11^{\mathrm{bB}}$ & $4,21 \pm 0,21^{\mathrm{bB}}$ & $3,39 \pm 0,11^{b c}$ \\
\hline 15 & $7,92 \pm 0,24^{\mathrm{aA}}$ & $7,06 \pm 0,26^{a B}$ & $5,23 \pm 0,19^{\mathrm{ac}}$ & $4,70 \pm 0,12^{\mathrm{aD}}$ & $5,13 \pm 0,12^{\mathrm{aC}}$ \\
\hline
\end{tabular}

Médias de 3 repetições \pm desvio padrão, seguidas de mesma letra minúscula na coluna e maiúscula na linha não diferem entre si, pelo Teste de Tukey ( $P<0,05)$. (T1) controle (mamão sem revestimento); (T2) 30\% de amido, 20\% de glicerol e 0,5\% de óleo essencial de cravo; (T3) 30\% de amido, 30\% de glicerol e 0,5\% de óleo essencial de cravo; (T4) $30 \%$ de amido, $20 \%$ de glicerol e $1 \%$ de óleo essencial de cravo; (T5) $30 \%$ de amido, $30 \%$ de glicerol e $1 \%$ de óleo essencial de cravo.

Means of 3 repetitions \pm standard deviation, followed by the same lowercase letter in the column and uppercase in the line do not differ from each other by the Tukey test ( $P<0.05$ ). (T1) control (uncoated papaya); (T2) 30\% starch, 20\% glycerol and $0.5 \%$ clove essential oil; (T3) 30\% starch, 30\% glycerol and 0.5\% clove essential oil; (T4) 30\% starch, $20 \%$ glycerol and $1 \%$ clove essential oil; (T5) $30 \%$ starch, $30 \%$ glycerol and $1 \%$ clove essential oil.

Houve um aumento na porcentagem de perda de massa das amostras de mamão em todos os tratamentos durante o período de armazenamento avaliado. Isso pode ocorrer, principalmente pelo tempo de armazenamento e pela transpiração (Carvalho \& Lima, 2002). Observou-se que no tratamento controle (T1), no final do período de avaliação perdeu 7,92\% de massa, valor maior do que quando comparado com as amostras que receberam as coberturas comestíveis, obtendo diferença significativa com os outros tratamentos. Já entre as amostras que receberam as coberturas, a que apresentou maior perda de massa foi o T2 com $7,06 \%$.

O tratamento em que houve menor perda de massa foi o $\mathrm{T} 4$, com $4,70 \%$ de perda de massa ao final das análises, não diferindo apenas do tratamento T5, que obteve $5,13 \%$ de perda. Os autores Santos et al. (2008), mostraram que perdas de massa acima de $5 \%$ são suficientes para depreciar o mamão, assim o tratamento T4 foi o único que ficou abaixo desse valor ao final de 15 dias.

Cortez-Vega et al. (2013), avaliou a perda de massa em mamão minimamente processado utilizando diferentes revestimentos à base de goma xantana e encontrou que a mesma foi efetiva na redução da perda de massa para esse fruto minimamente processado, obtendo menores valores de perda de massa $(5,30 \%)$, quando comparado a amostra controle que continha glicerol (14,95\%), em 12 dias de armazenamento a $4{ }^{\circ} \mathrm{C}$.

De acordo com Raybaudi-Massilia, Mosqueda-Melgar, Sobrino-López, SolivaFortuny, \& Martín-Belloso (2007), e Villalobos-Carvajal, Hernández-Muñoz, Albors \& Chiralt (2009), os revestimentos comestíveis podem reduzir a perda de massa, porque ajudam a diminuir a perda de água de produtos minimamente processados. Segundo os mesmos autores, geralmente os revestimentos em minimamente processados são utilizados com o principal intuito de reduzir a perda de massa. 


\section{b) Textura}

A Tabela 3 apresenta os valores de textura expressos em Newton em amostras de mamão minimamente processado com diferentes proporções de glicerol e óleo essencial de cravo.

Tabela 3. Textura $(\mathrm{N})$ de amostras de mamão minimamente processados revestidos com diferentes proporções de glicerol e óleo essencial de cravo e armazenadas a $4 \pm 1^{\circ} \mathrm{C}$, por 15 dias.

Table 3. Texture (N) of minimally processed papaya samples coated with different proportions of glycerol and essential oil of clove and stored at $4 \pm 1{ }^{\circ} \mathrm{C}$ for 15 days.

\begin{tabular}{cccccc}
\hline \multirow{2}{*}{ Dias } & \multicolumn{5}{c}{ Tratamentos } \\
\cline { 2 - 6 } & T1 (Controle) & $\mathrm{T} 2$ & $\mathrm{~T} 3$ & $\mathrm{~T} 4$ & $\mathrm{~T} 5$ \\
\hline 0 & $2,21 \pm 1,11^{\mathrm{aB}}$ & $4,00 \pm 1,88^{\mathrm{aAB}}$ & $3,95 \pm 0,48^{\mathrm{bAB}}$ & $7,20 \pm 2,32^{\mathrm{aA}}$ & $3,41 \pm 2,59^{\mathrm{aAB}}$ \\
1 & $3,91 \pm 1,3^{\mathrm{aAB}}$ & $2,23 \pm 0,63^{\mathrm{aB}}$ & $4,26 \pm 0,05^{\mathrm{bAB}}$ & $7,64 \pm 2,94^{\mathrm{aA}}$ & $2,36 \pm 1,11^{\mathrm{aA}}$ \\
3 & $3,68 \pm 3,19^{\mathrm{aB}}$ & $3,81 \pm 2,14^{\mathrm{aAB}}$ & $4,37 \pm 1,07^{\mathrm{bAB}}$ & $8,57 \pm 0,40^{\mathrm{aA}}$ & $5,68 \pm 0,62^{\mathrm{aA}}$ \\
5 & $1,49 \pm 0,42^{\mathrm{aB}}$ & $2,77 \pm 1,55^{\mathrm{aAB}}$ & $6,39 \pm 3,42^{\mathrm{abAB}}$ & $8,71 \pm 3,07^{\mathrm{aA}}$ & $5,63 \pm 0,41^{\mathrm{aA}}$ \\
7 & $3,23 \pm 0,85^{\mathrm{aAB}}$ & $2,02 \pm 0,52^{\mathrm{aB}}$ & $5,59 \pm 0,46^{\mathrm{abA}}$ & $5,84 \pm 1,60^{\mathrm{aA}}$ & $5,99 \pm 2,13^{\mathrm{aA}}$ \\
9 & $2,01 \pm 0,85^{\mathrm{aB}}$ & $2,58 \pm 0,01^{\mathrm{aB}}$ & $6,03 \pm 1,63^{\mathrm{abA}}$ & $5,46 \pm 1,19^{\mathrm{aA}}$ & $3,93 \pm 2,14^{\mathrm{aA}}$ \\
12 & $5,47 \pm 1,81^{\mathrm{aA}}$ & $5,48 \pm 0,70^{\mathrm{aA}}$ & $5,63 \pm 1,58^{\mathrm{abA}}$ & $6,94 \pm 0,41^{\mathrm{aA}}$ & $4,64 \pm 0,27^{\mathrm{aA}}$ \\
15 & $3,53 \pm 1,29^{\mathrm{aC}}$ & $1,99 \pm 0,46^{\mathrm{aC}}$ & $6,06 \pm 1,13^{\mathrm{aB}}$ & $6,96 \pm 1,12^{\mathrm{aA}}$ & $6,43 \pm 1,26^{\mathrm{aB}}$ \\
\hline
\end{tabular}

Médias de 3 repetições \pm desvio padrão, seguidas de mesma letra minúscula na coluna e maiúscula na linha não diferem entre si, pelo Teste de Tukey $(\mathrm{P}<0,05)$. ( $\mathrm{T} 1)$ controle (mamão sem revestimento), (T2) 30\% de amido, $20 \%$ de glicerol e $0,5 \%$ de óleo essencial de cravo; (T3) 30\% de amido, 30\% de glicerol e $0,5 \%$ de óleo essencial de cravo; (T4) 30\% de amido, $20 \%$ de glicerol e $1 \%$ de óleo essencial de cravo; (T5) 30\% de amido, $30 \%$ de glicerol e $1 \%$ de óleo essencial de cravo.

Means of 3 repetitions \pm standard deviation, followed by the same lowercase letter in the column and uppercase in the line do not differ from each other by the Tukey test $(P<0.05)$. (T1) control (uncoated papaya); (T2) 30\% starch, 20\% glycerol and 0.5\% clove essential oil; (T3) 30\% starch, 30\% glycerol and $0.5 \%$ clove essential oil; (T4) 30\% starch, 20\% glycerol and 1\% clove essential oil; (T5) 30\% starch, 30\% glycerol and $1 \%$ clove essential oil.

Observa-se que a firmeza da polpa se correlacionou à perda de massa, sendo melhor preservada e constante nos tratamentos com cobertura. Eficiência também foi demonstrada na conservação de mamão formosa a $10{ }^{\circ} \mathrm{C}$ por Rocha et al. (2005). Os tratamentos T4 e T5 obtiveram as menores porcentagens de perda de massa $(4,70 \%$ e $5,13 \%)$ e os maiores valores de textura $(6,96 \mathrm{~N}$ e $6,43 \mathrm{~N})$.

Com o decorrer do tempo de armazenamento e à medida que acontece o amadurecimento dos frutos, ocorre mudança na consistência do fruto, que está relacionada com o metabolismo dos hidratos de carbono e com as alterações da parede celular. Também as substâncias pécticas sofrem modificações marcantes, pela solubilização e despolarização, que acompanham o fruto durante o amadurecimento (Besinela et al., 2010). Alguns valores de textura em todos os tratamentos do presente trabalho, não seguiram uma ordem congruente, isso pode ocorrer devido às diferenças entre as amostras do mamão quanto ao comportamento fisiológico e bioquímico da fruta.

Um estudo realizado por Trigo et al. (2012) com revestimento de mamão minimamente processado com o uso de amido de arroz, alginato de sódio ou carboximetilcelulose, as médias de firmeza se mostraram com elevada variação em relação ao tempo de estocagem. Resultados semelhantes foram observados no presente estudo para os tratamentos T4 a $20 \%$ glicerol e $1 \%$ óleo essencial $(6,96 \mathrm{~N})$, 
T3 a 30\% glicerol e $0,5 \%$ óleo essencial $(6,06 \mathrm{~N})$ e T1 controle $(3,53 \mathrm{~N})$. O biofilme funciona como uma barreira física, retardando a perda da firmeza, as trocas gasosas assim como a taxa respiratória dos frutos, e o amadurecimento (Nunes, Neto, Nascimento, Oliveira, \& Mesquita, 2017).

\section{c) Acidez titulável}

A Tabela 4 apresenta os valores de acidez titulável encontrada para o mamão minimamente processado revestidos com fécula de mandioca, glicerol e óleos essencial de cravo, armazenados por $4{ }^{\circ} \mathrm{C}$ por 15 dias.

Tabela 4. Acidez titulável (\% ácido cítrico) de amostras de mamão minimamente processados revestidos com diferentes proporções de glicerol e óleo essencial de cravo e armazenadas a $4 \pm 1{ }^{\circ} \mathrm{C}$, por 15 dias.

Table 4. Titratable acidity (\% citric acid) of papaya minimally processed samples coated with different proportions of glycerol and essential oil of clove and stored at $4 \pm 1^{\circ} \mathrm{C}$ for 15 days.

\begin{tabular}{cccccc}
\hline \multirow{2}{*}{ Dias } & \multicolumn{5}{c}{ Tratamentos } \\
\cline { 2 - 6 } & $\mathrm{T} 1$ (Controle) & $\mathrm{T} 2$ & $\mathrm{~T} 3$ & $\mathrm{~T} 4$ & $\mathrm{~T} 5$ \\
\hline 0 & $0,081 \pm 0,003^{\mathrm{bA}}$ & $0,081 \pm 0,003^{\mathrm{bA}}$ & $0,081 \pm 0,003^{\mathrm{abA}}$ & $0,081 \pm 0,003^{\mathrm{aA}}$ & $0,081 \pm 0,003^{\mathrm{bA}}$ \\
1 & $0,049 \pm 0,020^{\mathrm{cA}}$ & $0,042 \pm 0,004^{\mathrm{cA}}$ & $0,044 \pm 0,004^{\mathrm{cA}}$ & $0,043 \pm 0,010^{\mathrm{aA}}$ & $0,052 \pm 0,008^{\mathrm{bA}}$ \\
3 & $0,047 \pm 0,002^{\mathrm{cA}}$ & $0,046 \pm 0,005^{\mathrm{cA}}$ & $0,049 \pm 0,000^{\mathrm{cA}}$ & $0,053 \pm 0,002^{\mathrm{aA}}$ & $0,059 \pm 0,010^{\mathrm{bA}}$ \\
5 & $0,079 \pm 0,009^{\mathrm{bA}}$ & $0,082 \pm 0,000^{\mathrm{bA}}$ & $0,084 \pm 0,017^{\mathrm{abA}}$ & $0,076 \pm 0,009^{\mathrm{aA}}$ & $0,077 \pm 0,008^{\mathrm{bA}}$ \\
7 & $0,049 \pm 0,010^{\mathrm{cA}}$ & $0,054 \pm 0,004^{\mathrm{cA}}$ & $0,066 \pm 0,014^{\mathrm{bcA}}$ & $0,050 \pm 0,008^{\mathrm{aA}}$ & $0,065 \pm 0,015^{\mathrm{bA}}$ \\
9 & $0,044 \pm 0,000^{\mathrm{cD}}$ & $0,079 \pm 0,006^{\mathrm{bB}}$ & $0,066 \pm 0,004^{\mathrm{bcC}}$ & $0,070 \pm 0,001^{\mathrm{aC}}$ & $0,095 \pm 0,003^{\mathrm{bA}}$ \\
12 & $0,136 \pm 0,000^{\mathrm{aA}}$ & $0,105 \pm 0,013^{\mathrm{aA}}$ & $0,094 \pm 0,001^{\mathrm{aA}}$ & $0,142 \pm 0,034^{\mathrm{aA}}$ & $0,161 \pm 0,041^{\mathrm{aA}}$ \\
15 & $0,145 \pm 0,006^{\mathrm{cC}}$ & $0,143 \pm 0,002^{\mathrm{cC}}$ & $0,161 \pm 0,023^{\mathrm{abA}}$ & $0,153 \pm 0,004^{\mathrm{aBC}}$ & $0,167 \pm 0,007^{\mathrm{bAB}}$ \\
\hline
\end{tabular}

Médias de 3 repetições \pm desvio padrão, seguidas de mesma letra minúscula na coluna e maiúscula na linha não diferem entre si, pelo Teste de Tukey $(P<0,05)$. (T1) controle (mamão sem revestimento); (T2) 30\% de amido, 20\% de glicerol e 0,5\% de óleo essencial de cravo; (T3) $30 \%$ de amido, $30 \%$ de glicerol e $0,5 \%$ de óleo essencial de cravo; (T4) $30 \%$ de amido, $20 \%$ de glicerol e $1 \%$ de óleo essencial de cravo; (T5) $30 \%$ de amido, $30 \%$ de glicerol e $1 \%$ de óleo essencial de cravo.

Means of 3 repetitions \pm standard deviation, followed by the same lowercase letter in the column and uppercase in the line do not differ from each other by the Tukey test ( $P<0.05$ ). (T1) control (uncoated papaya); (T2) 30\% starch, 20\% glycerol and $0.5 \%$ clove essential oil; (T3) 30\% starch, 30\% glycerol and $0.5 \%$ clove essential oil; (T4) 30\% starch, $20 \%$ glycerol and $1 \%$ clove essential oil; (T5) 30\% starch, 30\% glycerol and 1\% clove essential oil.

O mamão apresentou oscilações na acidez durante o armazenamento. A acidez total foi mostrando uma pequena variação até $07^{\circ}$ dia, não obtendo diferença significativa entre os valores por tratamento. Somente a partir do nono dia as amostras começaram a diferir significativamente.

Dessa forma, observa-se que a partir do $12^{\circ}$ dia obteve um aumento nos valores de todos os tratamentos, mantendo essa elevação até o $15^{\circ}$ dia, sendo o T2 o valor mais baixo $(0,143 \%$ de ácido cítrico), não diferindo do controle T1 $(0,145 \%)$ e T5 o valor mais alto $(0,167 \%$ de ácido cítrico), não diferindo apenas do T4 (0,153\% de ácido cítrico).

Os autores Rocha, Menezes, Nascimento, \& Nunes. (2007), trabalhando com mamão formosa refrigerado em diferentes temperaturas, verificaram redução da acidez total titulável (ATT) durante o armazenamento, observando, também, uma pequena elevação após os 28 dias. Fonseca, Cenci, Leal \& Botrel (2003) não verificaram diferenças significativas na ATT entre tratamentos, em mamão Golden armazenado em temperatura ambiente e a $10{ }^{\circ} \mathrm{C}$ e obtiveram valores próximos aos obtidos entre os dias 12 e 15 deste trabalho; desta forma, não houve redução do 
metabolismo dos frutos. Morais, Araújo, Machado, Ricarte \& Sales Junior, (2010) verificaram leve aumento da acidez durante o armazenamento de mamão formosa a $10{ }^{\circ} \mathrm{C}$ com filme de Polyamida X-tend, pois os mesmos colheram com $10 \%$ de coloração, estando em fase de amadurecimento.

Geralmente, o teor de acidez de frutos não excede $2 \%$ e, de acordo com o tipo de fruto, os níveis de acidez da casca e da polpa são variáveis. Uma possível explicação para os suaves acréscimos nos teores de ATT durante a parte final do experimento corresponde aos períodos em que a atividade respiratória dos frutos manteve em baixos índices, de forma a conservar os ácidos orgânicos (Chitarra \& Chitarra, 1990; Morais et al., 2010).

\section{d) Potencial Hidrogeniônico (pH)}

A acidez constitui fator de grande importância para o sabor e aroma dos frutos e, além disso, o pH influencia no escurecimento oxidativo dos tecidos vegetais. A diminuição do seu valor acarreta redução da velocidade de escurecimento do fruto (Freitas, Cortez-Vega, Pizato, Prentice-Hernández \& Borges, 2013). Os valores das análises de $\mathrm{pH}$ de mamões minimamente processados tratados com diferentes proporções de coberturas armazenadas a $4 \pm 1{ }^{\circ} \mathrm{C}$ durante 15 dias, são mostrados na Tabela 5.

Os valores de $\mathrm{pH}$ das amostras com cobertura diminuiram com o tempo de armazenamento assim como a amostra T1 (controle). De acordo com os resultados obtidos o $\mathrm{pH}$ das amostras que passaram pelo tratamento com cobertura (T2, T3, T4 e T5) variaram de 4,53 a 4,91 após 15 dias de armazenamento, que foi ligeiramente inferior ao $\mathrm{pH}$ inicial de mamão da amostra controle (T1).

$\mathrm{O}$ baixo $\mathrm{pH}$ é preferido em frutas frescas, pois permite controlar melhor o crescimento microbiano (Argañosa, Raposo, Teixeira \& Morais, 2008), o que indica neste trabalho os baixos valores de crescimento de bolores e leveduras e psicrotróficos.

Até o quinto dia de armazenamento, todos os tratamentos mostraram uma tendência a permanecer estável, entretanto o T2 foi o melhor para controlar seu pH tendo uma menor diferença significativa entre os dias de armazemento. Estas variações estão associadas à produção de ácidos orgânicos, como ácido málico e cítrico, decorrente das reações fisiológicas e bioquímicas (Lima, Ramos, Marcellini, Batista \& Faraoni, 2005) o que foi observado no presente trabalho.

Segundo Cortez-Vega, Pizato, Souza \& Prentice (2014), o pH do mamão diminuiu com o tempo, sendo que a amostra controle sem revestimento apresentou um $\mathrm{pH}$ mais baixo $(4,04)$ do que os outros tratamentos depois de 12 dias. Também esses mesmos autores relataram uma diminuição do $\mathrm{pH}$ com o passar dos dias de armazenamento para todas as amostras avaliadas. Comportamento semelhante foi encontrado neste trabalho.

De acordo com Pimentel et al. (2011), as variações de pH estariam atribuídas à degradação inicial e à posterior síntese de ácidos orgânicos com diferentes potenciais de dissociação iônica, sendo que o menor valor de pH estará associado a um nível mais avançado de maturação, o que justifica a amostra T1 (controle) possuir os valores mais baixos de $\mathrm{pH}$ entre os dias 5 e 12 . 
Tabela 5. Valores de $\mathrm{pH}$ de amostras de mamão minimamente processados revestidos com diferentes proporções de glicerol e óleo essencial de cravo e armazenadas a $4 \pm 1{ }^{\circ} \mathrm{C}$, por 15 dias.

Table 5. $\mathrm{pH}$ values of minimally processed papaya samples coated with different proportions of glycerol and essential oil of clove and stored at $4 \pm 1{ }^{\circ} \mathrm{C}$ for 15 days.

\begin{tabular}{cccccc}
\hline \multirow{2}{*}{ Dias } & \multicolumn{5}{c}{ Tratamentos } \\
\cline { 2 - 6 } & $\mathrm{T} 1$ (Controle) & $\mathrm{T} 2$ & $\mathrm{~T} 3$ & $\mathrm{~T} 4$ & $\mathrm{~T}$ \\
\hline 0 & $5,15 \pm 0,01^{\mathrm{bA}}$ & $5,15 \pm 0,01^{\mathrm{bA}}$ & $5,15 \pm 0,01^{\mathrm{deA}}$ & $5,15 \pm 0,01^{\mathrm{bcA}}$ & $5,15 \pm 0,01^{\mathrm{cdA}}$ \\
1 & $5,86 \pm 0,05^{\mathrm{aA}}$ & $5,60 \pm 0,04^{\mathrm{aB}}$ & $5,65 \pm 0,03^{\mathrm{aB}}$ & $5,51 \pm 0,01^{\mathrm{aC}}$ & $5,65 \pm 0,01^{\mathrm{aB}}$ \\
3 & $5,21 \pm 0,08^{\mathrm{bA}}$ & $5,29 \pm 0,07^{\mathrm{bA}}$ & $5,20 \pm 0,02^{\mathrm{cdA}}$ & $5,20 \pm 0,07^{\mathrm{bA}}$ & $5,20 \pm 0,07^{\mathrm{cdA}}$ \\
5 & $5,05 \pm 0,11^{\mathrm{bC}}$ & $5,25 \pm 0,11^{\mathrm{bA}}$ & $5,24 \pm 0,03^{\mathrm{cAB}}$ & $5,06 \pm 0,01^{\mathrm{cBC}}$ & $5,24 \pm 0,01^{\mathrm{cAB}}$ \\
7 & $5,18 \pm 0,10^{\mathrm{bB}}$ & $5,24 \pm 0,13^{\mathrm{bAB}}$ & $5,44 \pm 0,04^{\mathrm{bA}}$ & $5,18 \pm 0,00^{\mathrm{bB}}$ & $5,44 \pm 0,00^{\mathrm{bA}}$ \\
9 & $4,80 \pm 0,00^{\mathrm{cC}}$ & $5,15 \pm 0,07^{\mathrm{bA}}$ & $5,10 \pm 0,00^{\mathrm{eA}}$ & $4,95 \pm 0,07^{\mathrm{dB}}$ & $5,10 \pm 0,07^{\mathrm{dA}}$ \\
12 & $4,36 \pm 0,01^{\mathrm{dD}}$ & $5,20 \pm 0,00^{\mathrm{bA}}$ & $4,84 \pm 0,01^{\mathrm{fC}}$ & $5,08 \pm 0,02^{\mathrm{cB}}$ & $4,84 \pm 0,02^{\mathrm{eC}}$ \\
15 & $4,67 \pm 0,05^{\mathrm{cB}}$ & $4,91 \pm 0,01^{\mathrm{cA}}$ & $4,53 \pm 0,05^{\mathrm{gC}}$ & $4,91 \pm 0,01^{\mathrm{dA}}$ & $4,53 \pm 0,01^{\mathrm{fC}}$ \\
\hline
\end{tabular}

Médias de 3 repetições \pm desvio padrão, seguidas de mesma letra minúscula na coluna e maiúscula na linha não diferem entre si, pelo Teste de Tukey $(P<0,05)$. (T1) controle (mamão sem revestimento); (T2) $30 \%$ de amido, $20 \%$ de glicerol e 0,5\% de óleo essencial de cravo; (T3) 30\% de amido, 30\% de glicerol e 0,5\% de óleo essencial de cravo; (T4) $30 \%$ de amido, $20 \%$ de glicerol e $1 \%$ de óleo essencial de cravo; (T5) $30 \%$ de amido, $30 \%$ de glicerol e $1 \%$ de óleo essencial de cravo.

Means of 3 repetitions \pm standard deviation, followed by the same lowercase letter in the column and uppercase in the line do not differ from each other by the Tukey test ( $P<0.05$ ). (T1) control (uncoated papaya); (T2) 30\% starch, 20\% glycerol and $0.5 \%$ clove essential oil; (T3) 30\% starch, 30\% glycerol and 0.5\% clove essential oil; (T4) 30\% starch, 20\% glycerol and $1 \%$ clove essential oil; (T5) $30 \%$ starch, $30 \%$ glycerol and $1 \%$ clove essential oil.

\section{e) Teor de sólidos solúveis totais ('Brix)}

A Tabela 6 apresenta os valores de sólidos solúveis encontrados para o mamão minimamente processado revestidos com fécula de mandioca, glicerol e óleo essencial de cravo, armazenados por $4{ }^{\circ} \mathrm{C}$ por 15 dias.

Podemos observar que o teor de sólidos solúveis totais ( ${ }^{\circ} \mathrm{Brix}$ ) variou com o passar dos dias de armazenamento, aumentando levemente, entre o primeiro e o último dia de análise. A amostra controle foi a que obteve maior valor $\left(8,40^{\circ} \mathrm{Brix}\right)$ durante os 15 dias, diferindo dos outros tratamentos com cobertura. Este aumento acentuado dos valores de ${ }^{\circ}$ Brix observado no tratamento $\mathrm{T} 1$ pode estar relacionado com o acúmulo de açúcares pela perda de umidade (Costa \& Balbino, 2002), o que levou a um amadurecimento mais acentuado do fruto. Os resultados mostram que os tratamentos T3, T4 e T5 apresentaram os valores mais baixos, não diferindo entre si, o que impediu de certa forma o amadurecimento da fruta.

Os teores de sólidos solúveis totais no mamão minimamente processado, durante o período de armazenamento, apresentaram tendência de aumento. Estes resultados foram similares aos encontrados por Fernandes, Aroucha, Souza, Sousa \& Fernandes (2010) que avaliaram o efeito da cera de carnaúba e filme plástico de polietileno de baixa densidade "X-tend" sobre a vida útil pós-colheita de mamão 'Formosa' e também encontraram aumento do teor de sólidos solúveis com o passar dos dias de armazenamento.Os valores finais encontrados para sólidos solúveis totais no presente trabalho se encontram abaixo dos encontrados por Cortez-Vega et al. (2014) que utilizaram coberturas comestíveis de isolado proteico de corvina em mamão minimamente processado, encontrando valores finais de 11,1 a $12,5^{\circ} \mathrm{Brix}$. 
Tabela 6. Valores de Sólidos Solúveis Totais ( ${ }^{\circ} \mathrm{Brix}$ ) das amostras de mamão minimamente processado, revestidos com diferentes proporções de glicerol e óleo essencial de cravo e armazenados a $4 \pm 1{ }^{\circ} \mathrm{C}$, por 15 dias.

Table 6. Total Soluble Solids ('Brix) values of minimally processed papaya samples, coated with different proportions of glycerol and clove essential oil and stored at $4 \pm 1^{\circ} \mathrm{C}$ for 15 days.

\begin{tabular}{cccccc}
\hline \multirow{2}{*}{ Dias } & \multicolumn{5}{c}{ Tratamentos } \\
\cline { 2 - 6 } & T1 (Controle) & T2 & T3 & T4 \\
\hline 0 & $4,99 \pm 0,01^{\mathrm{cA}}$ & $4,99 \pm 0,01^{\mathrm{cA}}$ & $4,99 \pm 0,01^{\mathrm{cA}}$ & $4,99 \pm 0,01^{\mathrm{dA}}$ & $4,99 \pm 0,01^{\mathrm{cA}}$ \\
1 & $5,90 \pm 0,14^{\mathrm{cA}}$ & $5,00 \pm 0,00^{\mathrm{cA}}$ & $5,90 \pm 0,85^{\mathrm{bcA}}$ & $5,90 \pm 0,00^{\mathrm{cA}}$ & $4,90 \pm 0,14^{\mathrm{cA}}$ \\
3 & $9,50 \pm 0,71^{\mathrm{aA}}$ & $7,60 \pm 0,57^{\mathrm{abAB}}$ & $7,50 \pm 0,71^{\mathrm{abB}}$ & $8,30 \pm 0,28^{\mathrm{abAB}}$ & $8,25 \pm 1,06^{\mathrm{abAB}}$ \\
5 & $8,00 \pm 0,71^{\mathrm{bAB}}$ & $8,50 \pm 0,71^{\mathrm{aAB}}$ & $7,25 \pm 0,35^{\mathrm{abB}}$ & $8,50 \pm 0,71^{\mathrm{aAB}}$ & $9,50 \pm 0,71^{\mathrm{aA}}$ \\
7 & $8,10 \pm 0,14^{\mathrm{bAB}}$ & $8,70 \pm 0,42^{\mathrm{aA}}$ & $7,00 \pm 1,13^{\mathrm{abB}}$ & $7,80 \pm 0,14^{\mathrm{abAB}}$ & $8,00 \pm 0,71^{\mathrm{abAB}}$ \\
9 & $8,10 \pm 0,14^{\mathrm{bA}}$ & $7,95 \pm 0,21^{\mathrm{abA}}$ & $7,50 \pm 0,00^{\mathrm{abA}}$ & $8,05 \pm 0,07^{\mathrm{abA}}$ & $7,50 \pm 0,71^{\mathrm{bA}}$ \\
12 & $8,90 \pm 0,14^{\mathrm{abA}}$ & $6,85 \pm 0,49^{\mathrm{bC}}$ & $7,20 \pm 0,14^{\mathrm{abBC}}$ & $7,65 \pm 0,21^{\mathrm{bB}}$ & $7,00 \pm 0,00 \mathrm{~b}^{\mathrm{BC}}$ \\
15 & $8,40 \pm 0,00^{\mathrm{bA}}$ & $7,70 \pm 0,14^{\mathrm{abC}}$ & $7,80 \pm 0,00^{\mathrm{aC}}$ & $7,80 \pm 0,00^{\mathrm{abC}}$ & $8,05 \pm 0,07^{\mathrm{abB}}$ \\
\hline
\end{tabular}

Médias de 3 repetições \pm desvio padrão, seguidas de mesma letra minúscula na coluna e maiúscula na linha não diferem entre si, pelo Teste de Tukey $(P<0,05)$. (T1) controle (mamão sem revestimento); (T2) 30\% de amido, 20\% de glicerol e 0,5\% de óleo essencial de cravo; (T3) 30\% de amido, 30\% de glicerol e 0,5\% de óleo essencial de cravo; (T4) $30 \%$ de amido, $20 \%$ de glicerol e $1 \%$ de óleo essencial de cravo; (T5) 30\% de amido, 30\% de glicerol e $1 \%$ de óleo essencial de cravo.

Means of 3 repetitions \pm standard deviation, followed by the same lowercase letter in the column and uppercase in the line do not differ from each other by the Tukey test ( $P<0.05$ ). (T1) control (uncoated papaya); (T2) 30\% starch, 20\% glycerol and $0.5 \%$ clove essential oil; (T3) 30\% starch, 30\% glycerol and $0.5 \%$ clove essential oil; (T4) $30 \%$ starch, $20 \%$ glycerol and $1 \%$ clove essential oil; (T5) 30\% starch, 30\% glycerol and $1 \%$ clove essential oil.

f) Cor

Os dados médios dos parâmetros da cor ( $L^{*}, a^{*}, b^{*}$ e $\left.h^{*}\right)$ estão apresentados na Tabela 7.

Os valores dos parâmetros $L^{*}$ e do ângulo $h *$ não diferiram significativamente ao final das análises entre os tratamentos; já entre os dias, houve oscilações para os valores de $h^{*}$ com um ligeiro aumento após o $9^{\circ}$ dia e um decréscimo significativo para os outros parâmetros ( $L^{*}$, Chroma a* e Chroma $b^{*}$ ). Estes dados mostram que o processamento mínimo não levou à perda de coloração do produto, resultados semelhantes encontrados por Souza et al. (2005) que avaliou a qualidade de produtos minimamente processados de mamão 'Formosa', fatias e metades, armazenados sob diferentes temperaturas $\left(3^{\circ} \mathrm{C}, 6^{\circ} \mathrm{C}\right.$ e $\left.9^{\circ} \mathrm{C}\right)$.

Em relação à luminosidade $\left(\mathrm{L}^{*}\right)$ pode-se perceber que os valores diminuíram com o passar dos dias de armazenamento. O tratamento controle (T1) foi o que apresentou a maior taxa de diminuição da luminosidade $41 \%$ no último dia de armazenamento. Já o tratamento T4 foi o que apresentou menor perda de luminosidade $28,4 \%$, quando comparado aos outros tratamentos. Esses resultados corroboram com a pesquisa de Cortez-Vega et al. (2014), que observaram reduções na luminosidade de mamão minimamente processado ao final do armazenamento. Assim, a análise de luminosidade do mamão revestido comprova que o papel do revestimento em garantir visualmente a manutenção das amostras foi alcançado, tendo o controle escurecido.

Assim como para o Chroma a*, a diminuição nos valores de Chroma b* pode indicar um escurecimento oxidativo, concordando com Fontes, Sarmento, Spoto \& Dias (2008) que observaram nas polpas de maçãs tratadas com alginato apresentou a menor média de $L$ * (coloração mais escura) entre os tratamentos. 
Tabela 7. Cor de amostras de mamão minimamente processados revestidos com diferentes proporções de glicerol e óleo essencial de cravo e armazenadas a $4 \pm 1^{\circ} \mathrm{C}$, por 15 dias.

Table 7. Color of minimally processed papaya samples coated with different proportions of glycerol and clove essential oil and stored at $4 \pm 1{ }^{\circ} \mathrm{C}$ for 15 days.

\begin{tabular}{|c|c|c|c|c|c|c|}
\hline \multirow{2}{*}{$\begin{array}{c}\text { Parâmetros } \\
\text { analisados }\end{array}$} & \multirow{2}{*}{ Dias } & \multicolumn{5}{|c|}{ Tratamentos } \\
\hline & & T1 (Controle) & $\mathrm{T} 2$ & T3 & $\mathrm{T} 4$ & T5 \\
\hline \multirow{8}{*}{$L^{*}$} & 0 & $47,64 \pm 3,83^{\mathrm{aA}}$ & $42,97 \pm 1,53^{\mathrm{aA}}$ & $45,02 \pm 0,98^{\mathrm{aA}}$ & $45,30 \pm 5,17^{\mathrm{aA}}$ & $47,44 \pm 1,58^{\mathrm{aA}}$ \\
\hline & 1 & $42,51 \pm 4,21^{\mathrm{abA}}$ & $38,06 \pm 0,63^{\mathrm{bA}}$ & $42,03 \pm 4,99^{\mathrm{abc} A}$ & $42,41 \pm, 28^{\mathrm{aA}}$ & $42,78 \pm 6,17^{\mathrm{abA}}$ \\
\hline & 3 & $39,70 \pm 4,62^{\mathrm{abcA}}$ & $34,65 \pm 0,52^{\mathrm{bcA}}$ & $43,19 \pm 1,73^{\mathrm{abA}}$ & $44,10 \pm 6,82^{\mathrm{aA}}$ & $46,21 \pm 5,98^{\mathrm{aA}}$ \\
\hline & 5 & $37,72 \pm 3,10^{\mathrm{bcA}}$ & $32,76 \pm 1,95^{\mathrm{cdA}}$ & $39,59 \pm 3,85^{\mathrm{bcdA}}$ & $37,74 \pm 5,18^{\mathrm{aA}}$ & $35,88 \pm 3,81^{\mathrm{bA}}$ \\
\hline & 7 & $35,69 \pm 1,58^{\mathrm{bcA}}$ & $30,37 \pm 1,40^{\mathrm{dA}}$ & $37,02 \pm 3,15^{\mathrm{bcdA}}$ & $35,52 \pm 4,65^{\mathrm{aA}}$ & $33,96 \pm 2,02^{\mathrm{bA}}$ \\
\hline & 9 & $35,65 \pm 1,73^{\mathrm{bcA}}$ & $33,43 \pm 0,52^{\mathrm{cdA}}$ & $35,12 \pm 3,91^{\mathrm{bcdA}}$ & $35,38 \pm 6,20^{\mathrm{aA}}$ & $36,63 \pm 0,08^{b A}$ \\
\hline & 12 & $33,30 \pm 2,25^{\mathrm{cA}}$ & $31,18 \pm 1,22^{\mathrm{dA}}$ & $33,92 \pm 1,30^{\mathrm{cdA}}$ & $35,54 \pm 5,52^{\mathrm{aA}}$ & $34,99 \pm 0,35^{\mathrm{bA}}$ \\
\hline & 15 & $33,58 \pm 1,32^{\mathrm{cA}}$ & $30,71 \pm 1,15^{\mathrm{dA}}$ & $32,58 \pm 1,01^{\mathrm{dA}}$ & $35,28 \pm 5,15^{\mathrm{aA}}$ & $36,07 \pm 0,30^{\mathrm{bA}}$ \\
\hline \multirow{8}{*}{ Chroma a* } & 0 & $26,16 \pm 0,28^{\mathrm{aA}}$ & $23,64 \pm 1,44^{\mathrm{aAB}}$ & $21,52 \pm 1,05^{\mathrm{aAB}}$ & $21,23 \pm 1,51^{\mathrm{aB}}$ & $19,85 \pm 3,10^{\mathrm{abB}}$ \\
\hline & 1 & $25,54 \pm 0,14^{\mathrm{abA}}$ & $23,43 \pm 2,01^{\mathrm{aAB}}$ & $21,70 \pm 0,44^{\mathrm{aAB}}$ & $20,07 \pm 0,80^{\mathrm{aAB}}$ & $19,96 \pm 4,99^{\mathrm{abcB}}$ \\
\hline & 3 & $23,93 \pm 0,10^{\mathrm{abA}}$ & $19,65 \pm 3,88^{\mathrm{aAB}}$ & $18,63 \pm 1,17^{\mathrm{ab} A \mathrm{~B}}$ & $16,85 \pm 1,75^{\mathrm{bcdB}}$ & $20,93 \pm 4,02^{\mathrm{aAB}}$ \\
\hline & 5 & $19,00 \pm 3,24^{\mathrm{abc} A}$ & $12,43 \pm 2,68^{\mathrm{bB}}$ & $18,44 \pm 1,51^{\mathrm{abA}}$ & $14,87 \pm 0,24^{\mathrm{cdAB}}$ & $15,33 \pm 1,21^{\mathrm{abc} A \mathrm{~B}}$ \\
\hline & 7 & $18,11 \pm 5,16^{\mathrm{abc} A}$ & $12,63 \pm 0,95^{\mathrm{bA}}$ & $18,24 \pm 3,05^{\mathrm{abA}}$ & $18,59 \pm 0,41^{\mathrm{abA}}$ & $15,97 \pm 0,49^{\mathrm{abc} A}$ \\
\hline & 9 & $18,28 \pm 2,43^{\mathrm{abc} A}$ & $9,00 \pm 0,27^{\mathrm{bB}}$ & $13,76 \pm 3,57^{\mathrm{bc} A \mathrm{~B}}$ & $13,10 \pm 0,00^{\mathrm{d} A \mathrm{~B}}$ & $11,85 \pm 2,97^{\mathrm{CB}}$ \\
\hline & 12 & $17,54 \pm 1,64^{\mathrm{bcA}}$ & $9,16 \pm 0,86^{\mathrm{bB}}$ & $10,40 \pm 2,18^{\mathrm{CB}}$ & $16,59 \pm 1,06^{\mathrm{bcA}}$ & $14,39 \pm 0,46^{\mathrm{abc} A}$ \\
\hline & 15 & $13,55 \pm 4,94^{\mathrm{cA}}$ & $10,03 \pm 1,57^{\mathrm{bA}}$ & $8,85 \pm 0,49^{\mathrm{cA}}$ & $14,73 \pm 1,91^{\mathrm{cdA}}$ & $12,90 \pm 0,64^{\mathrm{bcA}}$ \\
\hline \multirow{8}{*}{ Chroma b* } & 0 & $28,69 \pm 3,59^{\mathrm{aA}}$ & $27,08 \pm 1,67^{\mathrm{aA}}$ & $22,82 \pm 0,54^{\mathrm{aA}}$ & $22,90 \pm 1,48^{\mathrm{aA}}$ & $27,70 \pm 5,49^{\mathrm{aA}}$ \\
\hline & 1 & $26,16 \pm 3,42^{\mathrm{abA}}$ & $23,28 \pm 0,08^{\mathrm{bA}}$ & $22,40 \pm 1,17^{\mathrm{aA}}$ & $17,60 \pm 6,31^{\mathrm{aA}}$ & $21,16 \pm 1,31^{\mathrm{abA}}$ \\
\hline & 3 & $21,25 \pm 2,76^{\mathrm{abA}}$ & $17,99 \pm 1,39^{\mathrm{cA}}$ & $19,70 \pm 4,14^{\mathrm{abA}}$ & $16,09 \pm 5,75^{\mathrm{aA}}$ & $20,81 \pm 0,66^{\mathrm{bA}}$ \\
\hline & 5 & $17,42 \pm 3,87^{\mathrm{abAB}}$ & $11,35 \pm 0,48^{\mathrm{d} A \mathrm{~B}}$ & $17,87 \pm 1,25^{\mathrm{abc} A}$ & $13,26 \pm 4,14^{\mathrm{aAB}}$ & $10,55 \pm 0,89^{\mathrm{cB}}$ \\
\hline & 7 & $15,95 \pm 4,31^{\mathrm{bA}}$ & $12,80 \pm 0,64^{\mathrm{dA}}$ & $19,00 \pm 3,39^{\mathrm{abA}}$ & $15,80 \pm 4,73^{\mathrm{aA}}$ & $11,44 \pm 0,57^{\mathrm{cA}}$ \\
\hline & 9 & $16,99 \pm 7,21^{\mathrm{abA}}$ & $10,01 \pm 1,67^{\mathrm{dA}}$ & $14,30 \pm 3,25^{\mathrm{bcdA}}$ & $12,23 \pm 0,00^{\mathrm{aA}}$ & $10,48 \pm 3,01^{\mathrm{cA}}$ \\
\hline & 12 & $18,25 \pm 2,93^{\mathrm{abA}}$ & $10,76 \pm 1,39^{\mathrm{dA}}$ & $11,21 \pm 1,35^{\mathrm{cdA}}$ & $16,59 \pm 5,12^{\mathrm{aA}}$ & $16,32 \pm 0,77^{\mathrm{bcA}}$ \\
\hline & 15 & $14,87 \pm 4,87^{\mathrm{bA}}$ & $12,30 \pm 1,23^{d A}$ & $9,67 \pm 0,30^{d A}$ & $17,77 \pm 7,06^{\mathrm{aA}}$ & $16,08 \pm 0,47^{\mathrm{bcA}}$ \\
\hline \multirow{8}{*}{$\begin{array}{c}\text { Ângulo de Hue } \\
\left(\mathrm{H}^{\circ}\right)\end{array}$} & 0 & $47,64 \pm 1,94^{\mathrm{aB}}$ & $48,89 \pm 1,55^{a b c A B}$ & $46,69 \pm 0,80^{a \mathrm{~B}}$ & $47,16 \pm 1,50^{\mathrm{abB}}$ & $54,38 \pm 4,30^{\mathrm{aA}}$ \\
\hline & 1 & $45,69 \pm 1,78^{\mathrm{aAB}}$ & $44,82 \pm 1,05^{\mathrm{cdAB}}$ & $45,90 \pm 0,80^{\mathrm{aAB}}$ & $41,25 \pm 3,56^{\mathrm{bB}}$ & $48,14 \pm 3,15^{\mathrm{abc} A}$ \\
\hline & 3 & $41,61 \pm 1,43^{\mathrm{aA}}$ & $42,48 \pm 2,63^{\mathrm{dA}}$ & $46,60 \pm 2,66^{\mathrm{aA}}$ & $44,71 \pm 3,75^{\mathrm{abA}}$ & $44,84 \pm 2,32^{\mathrm{bcA}}$ \\
\hline & 5 & $42,52 \pm 3,56^{\mathrm{aA}}$ & $42,41 \pm 1,58^{\mathrm{dA}}$ & $44,09 \pm 1,38^{\mathrm{aA}}$ & $41,71 \pm 2,19^{\mathrm{bA}}$ & $34,52 \pm 1,05^{\mathrm{eB}}$ \\
\hline & 7 & $41,36 \pm 4,73^{\mathrm{aAB}}$ & $45,38 \pm 0,79^{\mathrm{bcdA}}$ & $46,16 \pm 3,22^{\mathrm{aAB}}$ & $40,35 \pm 2,57 b^{A B}$ & $35,60 \pm 0,53^{\text {deB }}$ \\
\hline & 9 & $42,91 \pm 4,82^{\mathrm{aA}}$ & $48,04 \pm 0,97^{a b c} A$ & $46,10 \pm 3,41^{\mathrm{aA}}$ & $43,03 \pm 0,00^{\mathrm{ab}} \mathrm{A}$ & $41,49 \pm 2,99^{\mathrm{cdA}}$ \\
\hline & 12 & $46,13 \pm 2,29^{\mathrm{aA}}$ & $49,59 \pm 1,12^{\mathrm{ab}} \mathrm{A}$ & $47,15 \pm 1,77^{\mathrm{aA}}$ & $45,00 \pm 3,09^{\mathrm{abA}}$ & $48,60 \pm 0,62^{\mathrm{abA}}$ \\
\hline & 15 & $47,66 \pm 4,91^{\mathrm{aA}}$ & $50,80 \pm 1,40^{\mathrm{aA}}$ & $47,54 \pm 0,40^{\mathrm{aA}}$ & $50,34 \pm 4,48^{\mathrm{aA}}$ & $51,26 \pm 0,55^{\mathrm{abA}}$ \\
\hline
\end{tabular}

Médias de 3 repetições \pm desvio padrão, seguidas de mesma letra minúscula na coluna e maiúscula na linha não diferem entre si, pelo Teste de Tukey $(\mathrm{P}<0,05)$. (T1) controle (mamão sem revestimento); (T2) $30 \%$ de amido, $20 \%$ de glicerol e $0,5 \%$ de óleo essencial de cravo; (T3) 30\% de amido, 30\% de glicerol e 0,5\% de óleo essencial de cravo; (T4) 30\% de amido, $20 \%$ de glicerol e $1 \%$ de óleo essencial de cravo; (T5) 30\% de amido, 30\% de glicerol e 1\% de óleo essencial de cravo.

Means of 3 repetitions \pm standard deviation, followed by the same lowercase letter in the column and uppercase in the line do not differ from each other by the Tukey test ( $\mathrm{P}<0.05$ ). (T1) control (uncoated papaya); (T2) 30\% starch, $20 \%$ glycerol and $0.5 \%$ clove essential oil; (T3) 30\% starch, 30\% glycerol and 0.5\% clove essential oil; (T4) $30 \%$ starch, $20 \%$ glycerol and $1 \%$ clove essential oil; (T5) $30 \%$ starch, $30 \%$ glycerol and $1 \%$ clove essential oil. 


\section{g) Análises microbiológicas}

Não foi detectado presença de Salmonela ssp e a concentração de Escherichia coli foi menor que $10^{2} \mathrm{UFC} / \mathrm{g}$ nas amostras analisadas. Os produtos minimamente processados devem ser similares ao produto fresco, porém com qualidade microbiológica garantida pela redução dos microrganismos patogênicos e deteriorantes. A RDC $n^{\circ} 12$ de 2001 (Brasil, 2001) estabelece que para frutas frescas, "in natura", preparadas (descascadas ou selecionadas ou fracionadas) sanificadas, refrigeradas ou congeladas, para consumo direto, a bactéria salmonela ssp. deve estar ausente.

A Tabela 8 apresenta os valores de bolores e leveduras e psicrotróficos encontrados para os mamões minimamente processados revestidos com fécula de mandioca, glicerol e óleos essencial de cravo, armazenados por $4{ }^{\circ} \mathrm{C}$ por 15 dias.

Tabela 8. Valores encontrados para bolores e leveduras e psicotróficos em mamão minimamente processado revestido com diferentes proporções de glicerol e óleo essencial de cravo e armazenado a $4 \pm 1{ }^{\circ} \mathrm{C}$ por 15 dias.

Table 8. Values found for mold and yeast and psychotrophic in minimally processed papaya coated with different proportions of glycerol and clove essential oil and stored at $4 \pm 1{ }^{\circ} \mathrm{C}$ for 15 days.

\begin{tabular}{|c|c|c|c|c|c|c|}
\hline \multirow{2}{*}{ Microrganismos } & \multirow{2}{*}{ Dias } & \multicolumn{5}{|c|}{ Tratamentos } \\
\hline & & T1 (Controle) & $\mathrm{T} 2$ & T3 & $\mathrm{T} 4$ & T5 \\
\hline \multirow{8}{*}{$\begin{array}{l}\text { Bolores e leveduras } \\
\text { (UFC/g) }\end{array}$} & 0 & $1,51 \pm 0,23^{\mathrm{hA}}$ & $1,51 \pm 0,23^{h A}$ & $1,51 \pm 0,23^{g A}$ & $1,51 \pm 0,23^{\mathrm{eA}}$ & $1,51 \pm 0,23^{\mathrm{eA}}$ \\
\hline & 1 & $2,44 \pm 0,31^{\mathrm{gA}}$ & $2,13 \pm 0,09^{g A B}$ & $1,89 \pm 0,11^{\mathrm{fB}}$ & $1,78 \pm 0,08^{\mathrm{eB}}$ & $2,44 \pm 0,03^{\mathrm{dA}}$ \\
\hline & 3 & $3,58 \pm 0,19^{f A}$ & $3,04 \pm 0,11^{\mathrm{fBC}}$ & $2,79 \pm 0,09^{\mathrm{eCD}}$ & $2,58 \pm 0,13^{d D}$ & $3,18 \pm 0,12^{\mathrm{dB}}$ \\
\hline & 5 & $5,53 \pm 0,07^{\mathrm{eA}}$ & $4,48 \pm 0,10^{\mathrm{eB}}$ & $4,36 \pm 0,04^{\mathrm{dBC}}$ & $4,30 \pm 0,02^{\mathrm{cC}}$ & $4,46 \pm 0,05^{\mathrm{CBC}}$ \\
\hline & 7 & $6,49 \pm 0,32^{\mathrm{dA}}$ & $5,17 \pm 0,09^{d B}$ & $4,87 \pm 0,10^{\mathrm{CB}}$ & $4,52 \pm 0,12^{\mathrm{cB}}$ & $5,55 \pm 0,11^{\mathrm{cB}}$ \\
\hline & 9 & $7,27 \pm 0,11^{\mathrm{cA}}$ & $6,11 \pm 0,02^{c c}$ & $5,45 \pm 0,08^{\mathrm{bD}}$ & $5,31 \pm 0,08^{b D}$ & $6,33 \pm 0,09^{\mathrm{bB}}$ \\
\hline & 12 & $8,68 \pm 0,21^{\mathrm{bA}}$ & $6,91 \pm 0,12^{\mathrm{bB}}$ & $6,02 \pm 0,09^{\mathrm{ac}}$ & $5,90 \pm 0,03^{\mathrm{aC}}$ & $7,02 \pm 0,02^{\mathrm{abB}}$ \\
\hline & 15 & $9,43 \pm 0,22^{\mathrm{aA}}$ & $7,46 \pm 0,21^{\mathrm{aB}}$ & $6,31 \pm 0,12^{\mathrm{aC}}$ & $6,02 \pm 0,04^{\mathrm{aC}}$ & $7,62 \pm 0,21^{\mathrm{aB}}$ \\
\hline \multirow{8}{*}{$\begin{array}{l}\text { Psicrotróficos } \\
\text { (UFC/g) }\end{array}$} & 0 & $1,32 \pm 0,42^{\mathrm{eA}}$ & $1,32 \pm 0,42^{\mathrm{eA}}$ & $1,32 \pm 0,42^{\mathrm{fA}}$ & $1,32 \pm 0,42^{\mathrm{gA}}$ & $1,32 \pm 0,42^{f A}$ \\
\hline & 1 & $2,18 \pm 0,40^{\mathrm{eA}}$ & $1,79 \pm 0,53^{\mathrm{eA}}$ & $1,62 \pm 0,42^{\mathrm{fA}}$ & $1,58 \pm 0,21^{\mathrm{gA}}$ & $1,81 \pm 0,21^{\mathrm{fA}}$ \\
\hline & 3 & $3,67 \pm 0,08^{d A}$ & $2,83 \pm 0,12^{\text {deB }}$ & $2,42 \pm 0,08^{\mathrm{eC}}$ & $2,21 \pm 0,10^{f C}$ & $2,92 \pm 0,04^{\mathrm{eB}}$ \\
\hline & 5 & $5,67 \pm 0,71^{\mathrm{cA}}$ & $3,58 \pm 0,40^{\mathrm{cdB}}$ & $3,17 \pm 0,08^{\mathrm{eB}}$ & $3,18 \pm 0,04^{\mathrm{eB}}$ & $3,82 \pm 0,17^{\mathrm{dB}}$ \\
\hline & 7 & $7,08 \pm 0,62^{\mathrm{bA}}$ & $4,51 \pm 0,44^{\mathrm{CB}}$ & $4,08 \pm 0,05^{\mathrm{dB}}$ & $3,90 \pm 0,18^{\mathrm{dB}}$ & $4,38 \pm 0,09^{\mathrm{dB}}$ \\
\hline & 9 & $7,83 \pm 0,21^{\mathrm{abA}}$ & $5,14 \pm 0,35^{\mathrm{bcB}}$ & $4,90 \pm 0,08^{\mathrm{CB}}$ & $4,76 \pm 0,10^{\mathrm{CB}}$ & $5,42 \pm 0,17^{\mathrm{cB}}$ \\
\hline & 12 & $8,12 \pm 0,14^{\mathrm{abA}}$ & $6,70 \pm 0,87^{\mathrm{abB}}$ & $6,19 \pm 0,21^{\mathrm{bB}}$ & $5,98 \pm 0,04^{\mathrm{bB}}$ & $6,58 \pm 0,28^{\mathrm{bB}}$ \\
\hline & 15 & $8,78 \pm 0,56^{\mathrm{aA}}$ & $7,42 \pm 0,91^{\mathrm{aB}}$ & $7,08 \pm 0,18^{\mathrm{aB}}$ & $6,89 \pm 0,02^{\mathrm{aB}}$ & $7,82 \pm 0,14^{\mathrm{aAB}}$ \\
\hline
\end{tabular}

Médias de 3 repetições \pm desvio padrão, seguidas de mesma letra minúscula na coluna e maiúscula na linha não diferem entre si, pelo Teste de Tukey $(\mathrm{P}<0,05)$. (T1) controle (mamão sem revestimento); (T2) 30\% de amido, 20\% de glicerol e 0,5\% de óleo essencial de cravo; (T3) 30\% de amido, 30\% de glicerol e 0,5\% de óleo essencial de cravo; (T4) $30 \%$ de amido, $20 \%$ de glicerol e $1 \%$ de óleo essencial de cravo; (T5) 30\% de amido, 30\% de glicerol e $1 \%$ de óleo essencial de cravo.

Means of 3 repetitions \pm standard deviation, followed by the same lowercase letter in the column and uppercase in the line do not differ from each other by the Tukey test ( $P$ <0.05). (T1) control (uncoated papaya); (T2) 30\% starch, 20\% glycerol and $0.5 \%$ clove essential oil; (T3) 30\% starch, 30\% glycerol and 0.5\% clove essential oil; (T4) 30\% starch, 20\% glycerol and 1\% clove essential oil; (T5) 30\% starch, 30\% glycerol and 1\% clove essential oil.

Observando a Tabela 8, verifica-se que houve crescimento dos microrganismos analisados com o passar dos dias de armazenamento, sendo que o tratamento 
controle (T1) foi o apresentou maior crescimento tanto par bolores e leveduras, quanto para psicrotróficos, diferindo significativamente dos demais tratamentos ( $T 2$, T3, T4 e T5). Isso pode ser atribuído pelo fato da ausência de cobertura na amostra. O melhor tratamento foi o que T4, pois exerceu um melhor controle sobre o crescimento dos psicrotróficos e bolores e leveduras. Estes resultados apresentam similaridade com a pesquisa de Cortez-Vega et al. (2014) que estudaram a vida útil do mamão minimamente processado utilizando coberturas comestíveis a base de isolado proteico de corvina. De acordo com Kester e Fennema (1986), o uso de revestimentos de baixa permeabilidade a gases, como é o caso de polissacarídeos, reduz o acesso do oxigênio aos tecidos, minimizando as alterações microbiana, o que foi observado no presente trabalho.

Essa baixa contagem microbiana nos tratamentos T2, T3, T4 e T5 pode ter ocorrido devido a adição do óleo essencial à cobertura, uma vez que pesquisas têm citado as propriedades antibacterianas e antifúngicas das especiarias in natura, seus óleos essenciais e seus extratos. Várias plantas usadas para aromatizar alimentos são apontadas por apresentarem atividade antimicrobiana como, por exemplo, o cravo (Eugenia caryophyllata) (Silvestri et al., 2010).

A ANVISA (Agência Nacional de Vigilância Sanitária) não estabelece limites quanto à contagem de bolores e leveduras e aeróbios psicrotróficos para produtos minimamente processados. No entanto, o crescimento excessivo destes contaminantes compromete a aparência, o sabor e o aroma do produto, provocando uma redução na aceitação sensorial. Uma carga microbiana de $10^{6}$ UFC $\mathrm{g}^{-1}$ foi estabelecida como a população limite aceitável, já que em populações superiores a esta, substâncias tóxicas podem ser produzidas (Rojas-Graü, Tapia, Rodríguez, Carmona \& Martin-Belloso, 2007).

Pinheiro, Figueiredo, Figueiredo, Maia \& Souza (2005), avaliando microbiologicamente frutos de goiaba vermelha, manga, melão japonês, mamão 'Formosa' e abacaxi minimamente processados e comercializados em supermercados de Fortaleza, verificaram a presença de bolores e leveduras em todos os produtos, já na gôndola do supermercado. Assim, a utilização de coberturas pode auxiliar no controle de microrganismos melhorando e valorizando sua comercialização.

\section{h) Análise Sensorial}

A Tabela 9 apresenta os resultados encontrados para a avaliação sensorial de mamão minimamente processado com diferentes proporções de glicerol e óleo essencial de cravo e armazenadas a $4 \pm 1{ }^{\circ} \mathrm{C}$, por 15 dias.

Podemos observar que os valores foram diminuindo com o passar dos dias de armazenamento para todos os atributos avaliados. O tratamento T4 foi o que apresentou as notas mais altas ao final dos 15 dias de avaliação para todos os atributos avaliados e o tratamento controle (T1) as menores notas.

$\mathrm{Na}$ análise sensorial realizada por Chevalier et al. (2018), para melões minimamente processados, revestidos com isolado proteico de tilápia, foi encontrado valores próximos a este trabalho, demonstrando que o uso de coberturas em frutas minimamente processadas é eficaz para o retardamento das alterações sensoriais. 
Tabela 9. Análise sensorial de amostras de mamão minimamente processados revestidos com diferentes proporções de glicerol e óleo essencial de cravo e armazenadas a $4 \pm 1^{\circ} \mathrm{C}$, por 15 dias.

Table 9. Sensory analysis of minimally processed papaya samples coated with different proportions of glycerol and clove essential oil and stored at $4 \pm 1^{\circ} \mathrm{C}$ for 15 days.

\begin{tabular}{|c|c|c|c|c|c|c|}
\hline \multirow{2}{*}{$\begin{array}{c}\text { Parâmetros } \\
\text { analisados }\end{array}$} & \multirow{2}{*}{ Dias } & \multicolumn{5}{|c|}{ Tratamentos } \\
\hline & & T1 (Controle) & $\mathrm{T} 2$ & T3 & T4 & T5 \\
\hline \multirow{8}{*}{ Textura } & 0 & $5,0 \pm 0,1^{\mathrm{aA}}$ & $5,0 \pm 0,1^{\mathrm{aA}}$ & $5,0 \pm 0,1^{\mathrm{aA}}$ & $5,0 \pm 0,1^{\mathrm{abA}}$ & $5,0 \pm 0,1^{\mathrm{aA}}$ \\
\hline & 1 & $5,0 \pm 0,1^{\mathrm{aA}}$ & $5,0 \pm 0,1^{\mathrm{aA}}$ & $5,0 \pm 0,1^{\mathrm{aA}}$ & $5,0 \pm 0,1^{\mathrm{abA}}$ & $5,0 \pm 0,1^{\mathrm{aA}}$ \\
\hline & 3 & $4,7 \pm 0,1^{\mathrm{bB}}$ & $4,8 \pm 0,1^{\mathrm{ab} A \mathrm{~B}}$ & $5,0 \pm 0,1^{\mathrm{aA}}$ & $5,0 \pm 0,1^{\mathrm{abA}}$ & $4,8 \pm 0,1^{\mathrm{aAB}}$ \\
\hline & 5 & $4,0 \pm 0,1^{\mathrm{cB}}$ & $4,6 \pm 0,1^{\mathrm{bAB}}$ & $4,7 \pm 0,1^{\mathrm{bAB}}$ & $4,9 \pm 0,1^{\mathrm{aA}}$ & $4,5 \pm 0,1^{\mathrm{bAB}}$ \\
\hline & 7 & $3,0 \pm 0,1^{d C}$ & $4,2 \pm 0,1^{\mathrm{CB}}$ & $4,2 \pm 0,1^{\mathrm{CB}}$ & $4,5 \pm 0,1^{b c A}$ & $4,1 \pm 0,1^{\mathrm{cB}}$ \\
\hline & 9 & $2,4 \pm 0,1^{\mathrm{eD}}$ & $3,5 \pm 0,1^{d C}$ & $4,0 \pm 0,1^{\mathrm{CB}}$ & $4,3 \pm 0,1^{\mathrm{cA}}$ & $3,9 \pm 0,1^{\mathrm{cB}}$ \\
\hline & 12 & $2,0 \pm 0,1^{f D}$ & $3,2 \pm 0,1^{\mathrm{eC}}$ & $3,7 \pm 0,1^{\mathrm{dB}}$ & $4,0 \pm 0,1^{\mathrm{cA}}$ & $3,5 \pm 0,1^{\mathrm{dB}}$ \\
\hline & 15 & $1,8 \pm 0,1^{\mathrm{fD}}$ & $3,0 \pm 0,1^{\mathrm{eC}}$ & $3,5 \pm 0,1^{\mathrm{dB}}$ & $4,0 \pm 0,1^{\mathrm{cA}}$ & $3,0 \pm 0,1^{\mathrm{eC}}$ \\
\hline \multirow{8}{*}{ Cor } & 0 & $5,0 \pm 0,1^{\mathrm{aA}}$ & $5,0 \pm 0,1^{\mathrm{aA}}$ & $5,0 \pm 0,1^{\mathrm{aA}}$ & $5,0 \pm 0,1^{\mathrm{aA}}$ & $5,0 \pm 0,1^{\mathrm{aA}}$ \\
\hline & 1 & $5,0 \pm 0,1^{\mathrm{aA}}$ & $5,0 \pm 0,1^{\mathrm{aA}}$ & $5,0 \pm 0,1^{\mathrm{aA}}$ & $5,0 \pm 0,1^{\mathrm{aA}}$ & $5,0 \pm 0,1^{\mathrm{aA}}$ \\
\hline & 3 & $4,3 \pm 0,1^{\mathrm{bB}}$ & $5,0 \pm 0,1^{\mathrm{aA}}$ & $5,0 \pm 0,1^{\mathrm{aA}}$ & $5,0 \pm 0,1^{\mathrm{aA}}$ & $4,8 \pm 0,1^{\mathrm{aA}}$ \\
\hline & 5 & $4,0 \pm 0,1^{c c}$ & $4,8 \pm 0,1^{\mathrm{aA}}$ & $4,7 \pm 0,1^{\mathrm{bAB}}$ & $4,9 \pm 0,1^{\mathrm{aA}}$ & $4,5 \pm 0,1^{\mathrm{bB}}$ \\
\hline & 7 & $2,9 \pm 0,1^{\mathrm{dB}}$ & $4,5 \pm 0,1^{\mathrm{bA}}$ & $4,5 \pm 0,1^{\mathrm{bA}}$ & $4,5 \pm 0,1^{\mathrm{bA}}$ & $4,3 \pm 0,1^{\mathrm{bA}}$ \\
\hline & 9 & $2,7 \pm 0,1^{\mathrm{dC}}$ & $4,2 \pm 0,1^{\mathrm{cAB}}$ & $4,2 \pm 0,1^{\mathrm{CAB}}$ & $4,3 \pm 0,1^{\mathrm{bA}}$ & $4,0 \pm 0,1^{\mathrm{cB}}$ \\
\hline & 12 & $2,0 \pm 0,1^{\mathrm{ec}}$ & $4,0 \pm 0,1^{\mathrm{cdA}}$ & $3,8 \pm 0,1^{\mathrm{dAB}}$ & $4,0 \pm 0,1^{\mathrm{cA}}$ & $3,6 \pm 0,1^{\mathrm{dB}}$ \\
\hline & 15 & $1,7 \pm 0,1^{\mathrm{fD}}$ & $3,8 \pm 0,1^{\mathrm{dAB}}$ & $3,6 \pm 0,1^{\mathrm{dB}}$ & $4,0 \pm 0,1^{\mathrm{cA}}$ & $3,2 \pm 0,1^{\mathrm{eC}}$ \\
\hline \multirow{8}{*}{ Aroma } & 0 & $5,0 \pm 0,1^{\mathrm{aA}}$ & $5,0 \pm 0,1^{\mathrm{aA}}$ & $5,0 \pm 0,1^{\mathrm{aA}}$ & $5,0 \pm 0,1^{\mathrm{aA}}$ & $5,0 \pm 0,1^{\mathrm{aA}}$ \\
\hline & 1 & $5,0 \pm 0,1^{\mathrm{aA}}$ & $5,0 \pm 0,1^{\mathrm{aA}}$ & $5,0 \pm 0,1^{\mathrm{aA}}$ & $5,0 \pm 0,1^{\mathrm{aA}}$ & $5,0 \pm 0,1^{\mathrm{aA}}$ \\
\hline & 3 & $4,6 \pm 0,1^{\mathrm{bB}}$ & $4,9 \pm 0,1^{\mathrm{aA}}$ & $5,0 \pm 0,1^{\mathrm{aA}}$ & $5,0 \pm 0,1^{\mathrm{aA}}$ & $4,6 \pm 0,1^{b B}$ \\
\hline & 5 & $4,0 \pm 0,1^{c C}$ & $4,6 \pm 0,1^{\mathrm{bAB}}$ & $4,6 \pm 0,1^{\mathrm{bAB}}$ & $4,8 \pm 0,1^{\mathrm{aA}}$ & $4,4 \pm 0,1^{b B}$ \\
\hline & 7 & $3,2 \pm 0,1^{d c}$ & $4,3 \pm 0,1^{\mathrm{cAB}}$ & $4,3 \pm 0,1^{\mathrm{cAB}}$ & $4,4 \pm 0,1^{\mathrm{bA}}$ & $4,1 \pm 0,1^{\mathrm{cB}}$ \\
\hline & 9 & $2,8 \pm 0,1^{\mathrm{eD}}$ & $3,6 \pm 0,1^{d c}$ & $4,0 \pm 0,1^{\mathrm{dAB}}$ & $4,1 \pm 0,1^{\mathrm{cA}}$ & $3,8 \pm 0,1^{\mathrm{dB}}$ \\
\hline & 12 & $2,2 \pm 0,1^{\mathrm{fC}}$ & $3,5 \pm 0,1^{\mathrm{dAB}}$ & $3,6 \pm 0,1^{\mathrm{eAB}}$ & $3,7 \pm 0,1^{\mathrm{dA}}$ & $3,4 \pm 0,1^{\mathrm{eB}}$ \\
\hline & 15 & $1,8 \pm 0,1^{g D}$ & $3,3 \pm 0,1^{\mathrm{dB}}$ & $3,4 \pm 0,1^{\mathrm{eB}}$ & $3,7 \pm 0,1^{\mathrm{dA}}$ & $3,0 \pm 0,1^{\mathrm{fC}}$ \\
\hline
\end{tabular}

Médias de 3 repetições \pm desvio padrão, seguidas de mesma letra minúscula na coluna e maiúscula na linha não diferem entre si, pelo Teste de Tukey $(\mathrm{P}<0,05)$. (T1) controle (mamão sem revestimento); (T2) 30\% de amido, 20\% de glicerol e 0,5\% de óleo essencial de cravo; (T3) 30\% de amido, 30\% de glicerol e 0,5\% de óleo essencial de cravo; (T4) $30 \%$ de amido, $20 \%$ de glicerol e $1 \%$ de óleo essencial de cravo; (T5) 30\% de amido, 30\% de glicerol e $1 \%$ de óleo essencial de cravo.

Means of 3 repetitions \pm standard deviation, followed by the same lowercase letter in the column and uppercase in the line do not differ from each other by the Tukey test ( $P<0.05)$. (T1) control (uncoated papaya); (T2) 30\% starch, 20\% glycerol and $0.5 \%$ clove essential oil; (T3) 30\% starch, 30\% glycerol and 0.5\% clove essential oil; (T4) 30\% starch, 20\% glycerol and 1\% clove essential oil; (T5) 30\% starch, 30\% glycerol and 1\% clove essential oil.

\section{CONCLUSÃO}

Pode-se concluir que as diferentes coberturas utilizadas neste trabalho foram eficientes na conservação de mamão "Formosa" minimamente processado, quando comparado a amostra controle. Dos tratamentos avaliados, o tratamento T4 (30\% de amido, 20\% de glicerol e 1\% de óleo essencial de cravo) foi o que apresentou os melhores resultados, mostrando-se capaz de reduzir a perda de massa e sofrer mínimas alterações quando comparado com os outros tratamentos.

O uso do óleo essencial de cravo foi eficiente para manter a qualidade sensorial e retardar o crescimento microbiano de mamão minimamente processado. O revestimento T4, foi eficaz no aumento da vida útil, deixando o mamão seguro para consumo por mais tempo quando comparado com a amostra de controle. 


\section{CONTRIBUIÇÃO DOS AUTORES}

O autor FMSH realizou as análises e elaborou este artigo científico, os autores SP, NTF e PDS realizaram análises. A autora RAP auxiliou na elaboração do artigo cientifico e o autor WRCV delineou o experimento, orientou os alunos e auxiliou na elaboração do artigo científico.

\section{CONFLITO DE INTERESSE}

Os autores declararam que não há conflito de interesse.

\section{FINANCIAMENTO}

Os autores informaram que não receberam suporte financeiro para o desenvolvimento da pesquisa.

\section{REFERÊNCIAS BIBLIOGRÁFICAS}

AOAC. (2008). Official methods of analysis. 16th ed. Washington: Association of Official Analytical Chemists.

APHA - American Public Health Association. (2001). Compendium of methods for the microbiological examination of foods. Washington, DC. 676 p.

Argañosa, A. C. S., Raposo, M. F. J., Teixeira, P., \& Morais, A. M. (2008). Effect of cut-type on quality of minimally processed papaya. Journal of the Science of Food and Agriculture, 88 (12), 20502060. https://doi.org/10.1002/jsfa.3309

Bergo, P., Sobral, P. J. A., \& Prison, J. M. (2010). Effect of glycerol on physical properties of cassava starch films. Journal of Food Processing and Preservation, 34, 401-410. https://doi.org/10.1111/j.1745-4549.2008.00282.x

Besinela, E. J., Sinhorim, M. M., Camargo, M., Albrecht, C. R. M, Simões, M., \& Silva, C. F. (2010). Efeito de diferentes biopolímeros no revestimento de mamão (Carica papaya $\mathrm{L}$ ) minimamente processado. Revista Varia Scientia Agrárias, 1 (1), 131-142.

Brasil. (2001). Agência Nacional de Vigilância Sanitária. RDC n 12, de 2 de janeiro de 2001. Diário Oficial. Brasília, DF.

Cao, N., Fu, Y., \& He, J. (2007). Preparation and physical properties of soy protein isolate and gelatin composite films. Food Hydrocolloids, 21, 1153-1162.

https://doi.org/10.1016/j.foodhyd.2006.09.001

Carvalho, A. V., \& Lima, L. C. O. (2002). Qualidade de kiwis minimamente processados e submetidos a tratamento com ácido ascórbico, ácido cítrico e cloreto de cálcio. Pesquisa Agropecuária Brasileira, 37 (5), 679-685. http://dx.doi.org/10.1590/S0100204X2002000500013 
Chevalier, R. C., Silva, G. F., Silva, D. M., Pizato, S., \& Cortez-Vega, W. R. (2016). Utilização de revestimento comestível à base de quitosana para aumentar a vida útil de melão minimamente processado. Journal of Bioenergy and Food Science, 3 (3), 130-138. DOI:10.18067/jbfs.v3i3.101

Chevalier, R. C., Pizato, S., De Lara, J. A. F., \& Cortez-Vega, W. R. (2018). Obtaining protein isolate of tilapia (Oreochromis niloticus) and its application as coating in fresh-cut melos. Journal of Food Safety, 38, e12496. https://doi.org/10.1111/jfs.12496

Chitarra, M.I.F., \& Chitarra, A.B.(1990). Pós-colheita de frutos e hortaliças. Lavras, MG: Escola Superior de Agricultura de Lavras.

Coma, V. (2008). Bioactive packaging technologies for extended shelf life of meat-based products. Meat Science, Barking, 78, (1-2), 90-103. https://doi.org/10.1016/j.meatsci.2007.07.035

Cortez-Vega, W. R., Piotrowicz, I. B. B., Prentice, C., \& Borges, C. D. (2013). Conservação de mamão minimamente processado com uso de revestimento comestível à base de goma xantana. Semina: Ciências Agrárias, 34, (4), 1753-1764. DOI: 10.5433/1679-0359.2013v34n4p1753

Cortez-Vega, W. R., Pizato, S., Souza, J. T. A., \& Prentice, C. (2014). Using edible coatings fromWhitemouth croaker (Micropogonias furnieri) protein isolate and organo-clay nanocomposite for improve the conservation properties of fresh-cut 'Formosa' papaya. Innovative Food Science and Emerging Technologies, 22, 197-202. https://doi.org/10.1016/j.ifset.2013.12.007

Costa, A. F. S. \& Balbino, J. M. S. (2002). Características da fruta para exportação e normas de qualidade. Embrapa, 21, 12-18.

Fernandes, P. L. O., Aroucha, E. M. M., Souza, P. A., Sousa, A. E. D., \& Fernandes, P. L. O. (2010). Qualidade de mamão 'Formosa' produzido no RN e armazenado sob atmosfera passiva. Revista Ciência Agronômica, 41 (4), 599-604. http://dx.doi.org/10.1590/S180666902010000400012

Fonseca, M. J. O., Cenci, S. A., Leal, N. R., Botrel, N. (2003). Uso de atmosfera controlada para conservação pós-colheita do mamão golden. Revista Brasileira de Fruticultura, 25 (3), 537-539.

Fontes, L. C. B., sarmento, S. B. S. S., Spoto, M. H. F., \& Dias, C. T. (2008). Conservação de maçã minimamente processada com o uso de películas comestíveis. Ciência e Tecnologia de Alimentos, 28 (4), 872-880. https://doi.org/10.1590/S0101-20612008000400017

Freitas, I. R., Cortez-Vega, W. R., Pizato, S., Prentice-Hernández, C., \& Borges, C. D. (2013). Xanthan gum as a carrier of preservative agents and calcium chloride applied on fresh-cut apple. Journal of Food Safety, 33 (3), 229-238. doi: 10.1111/jfs.12044

Kester, J., \& Fennema, O. (1986). Edible Films and Coatings: A Review. Food Technology, 40 (12), 47-59. 
Lima, A. S., Ramos, A. L. D., Marcellini, P. S., Batista, R. A., \& Faraoni, A. S. (2005). Adição de Agentes antiescurecimento, antimicrobiano e utilização de diferentes filmes plásticos em mamão minimamente processado. Revista Brasileira de Fruticultura, 27 (1), 149-152. https://doi.org/10.1590/S0100-29452005000100039

Mendonça, V., Abreu, N. A. A., Gurgel, R. L. S., Ferreira, E. A., Orbes, M. Y., \& Tosta, M. S. (2006). Crescimento de mudas de mamoeiro 'Formosa' em substratos com utilização de composto orgânico superfosfato simples. Ciência e Agrotecnologia, 30 (5), 861-868. http://dx.doi.org/10.1590/ S1413-70542006000500006

Minolta. (1994). Precise color communication: color control from feeling to instrumentation. Osaka: Co. Ltda. 49 p.

Morais, F. A., Araújo, F. M. M. C., Machado, A. V., Ricarte, F. D. N., \& Sales Junior, R. (2010). Influência da atmosfera modificada sob a vida útil pós-colheita do mamão 'Formosa'. Revista Verde, 5 (4), 01-09.

Moretti, C. L. (2007). Panorama do processamento mínimo de frutas e hortaliças. In: Moretti, C. L. Manual de processamento mínimo de frutas e hortaliças. Brasília: Embrapa Hortaliças, cap. 4, p. 25-40.

Nunes, A. C. D., Neto, A. F., Nascimento, I. K. S., Oliveira, F. J. V., \& Mesquita, R. V. C. (2017). Armazenamento de mamão formosa revestido à base de fécula de mandioca. Revista de Ciências Agrárias, 40, (1), 254-263. https://doi.org/10.19084/RCA16048

Pereira, M. E.C., Silva, A. S., Bispo, A. S. R., Santos, D. B., Santos, S. B., \& Santos, V. J. (2006). Amadurecimento de mamão formosa com revestimento comestível à base de fécula de mandioca. Ciência e Agrotecnologia, 30 (6), 1116-1119. http://dx.doi.org/10.1590/S141370542006000600011

Perera, N., Gamage, T. V., Wakeling, L., Gamlath, G. G. S., \& Versteeg, C. (2010). Colour and texture of apples high pressure processed in pineapple juice. Innovative Food Science and Emerging Technologies, 11, (3), 39-46, 2010. https://doi.org/10.1016/j.ifset.2009.08.003

Pimentel, J. D. R., Souza, D. S., Oliveira, T. V., Oliveira, M. C., Bastos, V. S., \& Castro, A. A. (2011). Estudo da conservação de mamão Havaí utilizando películas comestíveis a diferentes temperaturas. Scientia Plena, 7 (10), 1-6.

Pinheiro, N. M. S., Figueiredo, E. A. T., Figueiredo, R. W., Maia, G. A., \& Souza, P. H. M. (2005). Avaliação da qualidade microbiológica de frutos minimamente processados comercializados em supermercados de Fortaleza. Revista Brasileira de Fruticultura, 27 (1), 153-156. http://dx.doi.org/10.1590/S0100-29452005000100040

Raybaudi-Massilia, R. M., Mosqueda-Melgar, J., Sobrino-López, A., Soliva-Fortuny, R., \& MartínBelloso, O. (2007). Shelf-life extension of fresh-cut "Fuji" apples at different ripeness stages using natural substances. Postharvest Biology and Technology, 45, 265-275. https://doi.org/10.1016/j.postharvbio.2007.02.006 
Rocha, R. H. C., Menezes, J. B., Nascimento, S. R. C., \& Nunes, G. H. R. (2007). Qualidade do mamão formosa submetido a diferentes temperaturas de refrigeração. Caatinga, 20 (1), 75-80.

Rocha, R. H. C., Nascimento, S. R. C., Menezes, J. B., Nunes, G. H. S., \& Silva, E. O. (2005). Qualidade pós-colheita do mamão Formosa armazenado sob refrigeração. Revista Brasileira de Fruticultura, 27 (3), 386-389. https://doi.org/10.1590/S0100-29452005000300012

Rojas-Graü, M. A., Soliva-Fortuny, R. C., \& Martín- Belloso, O. (2009). Edible coatings to incorporate active ingredients to fresh-cut fruits: a review. Trends in Food Science and Technology, 20, 438-447. https://doi.org/10.1016/j.tifs.2009.05.002

Rojas-Graü, M. A., Tapia, M. S., Rodríguez, F. J., Carmona, A. J., \& Martin-Belloso, O. (2007). Alginate and gellan-based edible coatings as carriers of antibrowning agents applied on freshcut Fuji apples. Food Hydrocolloids, 21 (1), 118-127. https://doi.org/10.1016/j.foodhyd.2006.03.001

Santos, C. E. M., Couto, F. A. D., Salomão, L. C. C., Cecon, P. R., Wagner Júnior, A., \& Bruckner, C. H. (2008). Comportamento pós-colheita de mamões formosa 'Tainung 01' acondicionados em diferentes embalagens para o transporte. Revista Brasileira de Fruticultura, 30 (2), 315-321. http://dx.doi.org/10.1590/S0100-29452008000200008

Silva, A. V. C., Oliveira, P. Y., Carnelossi, M. A. G., Muniz, E. N., \& Narain, N. (2009). Temperatura e embalagem para abóbora minimamente processada. Ciência e Tecnologia de Alimentos, 29, (2), 391-394. https://doi.org/10.1590/S0101-20612009000200025

Silvestri, J. D. F., Paroul, N., Czyewski, E., Lerin, L., Rotava, I., Cansian, R. L., Mossi, A., Toniazzo, G., Oliveira, D., \& Treichel, H. (2010). Perfil da composição química e atividades antibacteriana e antioxidante do óleo essencial do cravo-da-índia (Eugenia caryophyllata Thunb.). Revista Ceres, 57 (5), 589-594. http://dx.doi.org/10.1590/S0034-737X2010000500004

Souza, B. S., Durigan, J. F., Donadon, J. R., \& Lima, M. A. (2005). Qualidade e comportamento fisiológico do mamão "Formosa" minimamente processado. Brazilian Journal of Food Technology, 8, (3), 243-247.

Tapia, M. S., Rojas-Grau, M. A., Carmona, A., Rodríguez, F. J., Soliva- Fortuny, R., \& Martinbelloso, O. (2008). Use of alginate- and gellan-based coatings for improving barrier, texture and nutritional properties of fresh-cut papaya. Food Hydrocolloids, 22 (8), 1493-1503. https://doi.org/10.1016/j.foodhyd.2007.10.004

Trigo, J. M., Albertini, S., Spoto, M. H. F., Bruder, S., \& Sarmento, S. (2012). Efeito de revestimentos comestíveis na conservação de mamões minimamente processados. Brazilian Journal of Food Technology, 15 (2), 125-133. http://dx.doi.org/10.1590/S1981-67232012005000005

Villalobos-Carvajal, R., Hernández-Muñoz, P., Albors, A., \& Chiralt, A. (2009). Barrier and optical properties of edible hydroxypropyl methylcellulose coatings containing surfactants applied to fresh cut carrot slices. Food Hydrocolloids, 23 (2), 526-535. https://doi.org/10.1016/j.foodhyd.2008.02.008. 